\title{
Dendritic Calcium Encodes Striatal Neuron Output during Up-States
}

\author{
Jason N. D. Kerr and Dietmar Plenz \\ Unit of Neural Network Physiology, Laboratory of Systems Neuroscience, National Institute of Mental Health, Bethesda, \\ Maryland 20892
}

\begin{abstract}
Striatal spiny projection neurons control basal ganglia outputs via action potential bursts conveyed to the globus pallidus and substantia nigra. Accordingly, burst activity in these neurons contributes importantly to basal ganglia function and dysfunction. These bursts are driven by multiple corticostriatal inputs that depolarize spiny projection neurons from their resting potential of approximately $-85 \mathrm{mV}$, which is the down-state, to a subthreshold up-state of $-55 \mathrm{mV}$. To understand dendritic processing of bursts during up-states, changes in intracellular calcium concentration $\left(\left[\mathrm{Ca}^{2+}\right]_{i}\right)$ were measured in striatal spiny projection neurons from cortex-striatum-substantia nigra organotypic cultures grown for 5-6 weeks using somatic whole-cell patch recording and Fura-2. During up-states, $\left[\mathrm{Ca}^{2+}\right]_{i}$ transients at soma and primary, secondary, and tertiary dendrites were highly correlated with burst strength (i.e., the number of spontaneous action potentials). During down-states, the action potentials evoked by somatic current pulses elicited $\left[\mathrm{Ca}^{2+}\right]_{\mathrm{i}}$
\end{abstract}

Spiny projection neurons in the striatum play a major role in linking cortical activity to basal ganglia outputs. Their dendrites receive the majority of basal ganglia inputs from the cortex and their axons directly innervate basal ganglia output neurons (for review, see Gerfen and Wilson, 1996). Action potential bursts in spiny projection neurons correlate with important aspects of basal ganglia function, such as movement initiation and regulation of ongoing movements (DeLong, 1973; Crutcher and DeLong, 1984; Hikosaka et al., 1989; Kimura et al., 1992; Jaeger et al., 1993). Furthermore, changes in spiny projection neuron firing correlate with behavioral learning that relies on basal ganglia function (Tremblay et al., 1998; Jog et al., 1999). Similarly, dysfunction of striatal activity is directly linked to diseases of the basal ganglia (for review, see Albin et al., 1989). Given the importance of this burst activity in basal ganglia function, the question arises as to how information about bursts is processed within these neurons.

Somatic bursts are critical for modification of glutamatergic synapses in the cortex (Magee and Johnston, 1997; Markram et al., 1997) and are likely to be important for modification of corticostriatal glutamatergic synapses as well, which have been

\footnotetext{
Received Aug. 28, 2001; revised Nov. 26, 2001; accepted Nov. 30, 2001.

We thank Veronica Karpiak for expert technical assistance with the preparation of cultures; Drs. J. Beggs, U. Czubayko, J. Diamond, C. Gerfen, and S. Wise for comments on a previous version of this manuscript; and Dr. R. Ravin for helpful discussions early in the study.

Correspondence should be addressed to Dr. Dietmar Plenz, Unit of Neural Network Physiology, Laboratory of Systems Neuroscience, National Institute of Mental Health, Building 36, Room 2D-26, 9000 Rockville Pike, Bethesda, MD 20892. E-mail: dplenz@codon.nih.gov.

Copyright (ㄷ) 2002 Society for Neuroscience $\quad 0270-6474 / 02 / 221499-14 \$ 15.00 / 0$
}

transients in higher-order dendrites that were also correlated with burst strength. Evoked bursts during up-states increased dendritic $\left[\mathrm{Ca}^{2+}\right]_{i}$ transients supralinearly by $>200 \%$ compared with the down-state. In the presence of tetrodotoxin, burst-like voltage commands failed to elicit $\left[\mathrm{Ca}^{2+}\right]_{i}$ transients at higherorder dendrites. Thus, dendritic $\left[\mathrm{Ca}^{2+}\right]_{i}$ transients in spiny projection neurons encode somatic bursts supralinearly during up-states through active propagation of action potentials along dendrites. We suggest that this conveys information about the contribution of a spiny projection neuron to a basal ganglia output specifically back to the corticostriatal synapses involved in generating these outputs.

Key words: action potential backpropagation; forward propagation; calcium; Fura-2; organotypic culture; spiny projection neuron; dendritic processing; up-state; down-state; cortex; striatum; substantia nigra; electrophysiology; imaging

shown to be highly plastic (Lovinger et al., 1993; Calabresi et al., 1994; Akopian et al., 2000; Reynolds and Wickens, 2000; Kerr and Wickens, 2001). For corticostriatal synapses to take advantage of information about somatic bursts in spiny projection neurons, this information must be present in the dendrites, which are the main targets of corticostriatal inputs. One mechanism for conveying this information would involve changes in dendritic $\left[\mathrm{Ca}^{2+}\right]_{i}$ attributable to backpropagation of somatic action potentials into dendrites (for review, see Häusser et al., 2000).

Bursts in spiny projection neurons only occur during up-states, which are signaled by a transition in intracellular membrane potential from $-85 \mathrm{mV}$ to a subthreshold range at approximately $-55 \mathrm{mV}$. Up-states occur in vivo (Wilson and Kawaguchi, 1996; Stern et al., 1997; Reynolds and Wickens, 2000) and in striatal cultures receiving cortical inputs (Plenz and Aertsen, 1996; Plenz and Kitai, 1998). They are blocked by decortication (Wilson et al., 1983) or glutamate antagonists (Plenz and Kitai, 1998) and therefore indicate critical periods in dendritic processing that result from multiple corticostriatal inputs.

The restriction that bursts only occur during up-states in spiny projection neurons poses several potential problems for backpropagation of somatic action potentials. In cortical pyramidal neurons, backpropagation occurs at rest in vitro (Stuart and Sakmann, 1994; Stuart et al., 1997b; Häusser et al., 2000) but can fail in the presence of many synaptic inputs in vivo (Svoboda et al., 1999). Striatal neurons receive numerous inhibitory inputs from fast-spiking interneurons during up-states (Plenz and Kitai, 1998; Koos and Tepper, 1999), which could potentially suppress backpropagation, as shown in the hippocampus (Kim et al., 1995; 
Buzsaki et al., 1996; Tsubokawa and Ross, 1996). Finally, spiny projection neurons express A-currents (Surmeier et al., 1989; Nisenbaum and Wilson, 1995) that are active during the up-state and, if present at dendrites, might prevent backpropagation (Hoffman et al., 1997).

\section{MATERIALS AND METHODS}

Preparation of organotypic cultures. For the preparation of cortexstriatum-substantia nigra organotypic cultures (Plenz and Kitai, 1998), coronal sections from rat brains (Sprague Dawley, Taconic Farms, MD) at postnatal days $0-2$ were cut on a vibroslicer (VT $1000 \mathrm{~S}$; Leica Microsystems Inc., Allendale, NJ). Slices containing striatum $(500 \mu \mathrm{m}$ thickness) and cortex (350 $\mu \mathrm{m}$ thickness) were used for dissection of dorsal or dorsolateral cortical and striatal tissue. For the substantia nigra (including the pars compacta and pars reticulata), ventrolateral sections from $500-\mu \mathrm{m}$-thick mesencephalic slices were taken; medial tissue regions were avoided. The tissue was submerged in $25 \mu \mathrm{l}$ of chicken plasma (Sigma, St. Louis, MO) on a coverslip and $25 \mu$ l of bovine thrombin was added (1000 National Institutes of Health units/0.75 ml; Sigma). After plasma coagulation, individual cultures were placed in tubes (Nunc Inc., Naperville, IL) with $800 \mu \mathrm{l}$ of culture medium consisting of $50 \%$ basal Eagle's medium, $25 \%$ HBSS and $25 \%$ horse serum, $0.5 \%$ glucose, and 0.5 mM L-glutamine (all from Invitrogen, Grand Island, NY). Cultures were rotated in a "rollertube" incubator (0.6 rpm; Heraeus, Göttingen, Germany) at $35.5^{\circ} \mathrm{C}$ in normal atmosphere. After 3 and $27 \mathrm{~d}$ in vitro, $10 \mu \mathrm{l}$ of mitosis inhibitor was added for $24 \mathrm{hr}(4.4 \mathrm{~mm}$ cytosine-5-b-arabinofuranosid, $4.4 \mathrm{~mm}$ uridine, and $4.4 \mathrm{~mm} 5$-fluorodeoxyuridine; calculated to a final concentration; all from Sigma). Medium was changed every 3-5 d.

Whole-cell patch recordings. For electrophysiological recording, the cultures were submerged in artificial CSF (ACSF) containing (in $\mathrm{mM}$ ): $126 \mathrm{NaCl}, 0.3 \mathrm{NaH}_{2} \mathrm{PO}_{4}, 2.5 \mathrm{KCl}, 0.3 \mathrm{KH}_{2} \mathrm{PO}_{4}, 1.6 \mathrm{CaCl}_{2}, 1.0 \mathrm{MgCl}_{2}, 0.4$ $\mathrm{MgSO}_{4}, 26.2 \mathrm{NaHCO}_{3}$, and $11 \mathrm{D}$-glucose saturated with $95 \% \mathrm{O}_{2}$ and $5 \%$ $\mathrm{CO}_{2}$. The osmolarity of the ACSF was at $300 \pm 5 \mathrm{mOsm}$. Bath temperature was continuously monitored and maintained at $35.5 \pm 0.5^{\circ} \mathrm{C}$ (TC20; NPI, Tamm, Germany). The recording chamber was mounted on an inverted microscope (IX-70; Olympus Optical, Tokyo, Japan) that had been placed on a custom-made sliding table allowing for a change in field of view during the experiment.

Patch pipettes for somatic whole-cell recordings were pulled $(1.5 \mathrm{~mm}$ outer diameter, 0.75 inner diameter; P-97; Sutter Instruments, Novato, CA) and fire polished (MF-830; Narishige, Tokyo, Japan). The intracellular patch solution contained (in $\mathrm{mm}$ ): $132 \mathrm{~K}$-gluconate, $6 \mathrm{KCl}, 8 \mathrm{NaCl}$, 10 HEPES, $2 \mathrm{Mg}$-ATP, $0.39 \mathrm{Na}$-GTP. The solution was supplemented with $100 \mu \mathrm{M}$ Fura-2 (pentapotassium salt; Molecular Probes, Eugene, OR) and $0.2 \%$ Neurobiotin (Vector Laboratories, Burlingame, CA). The $\mathrm{pH}$ was adjusted to 7.2-7.4 with $\mathrm{KOH}$ and the final osmolarity of the pipette solution was at $290 \pm 10 \mathrm{mOsm}$. The open resistance of the pipettes was 4-6 M $\Omega$. To reduce degradation of ATP, GTP, and Fura-2, the intracellular working solution was kept on ice in a darkened room throughout the experiment before backfilling of electrodes.

Intracellular signals were recorded using an Axopatch 1-D amplifier with a CV-4 $1 \times$ head stage (Axon Instruments, Foster City, CA). After the formation of a Giga-seal, electrode capacitance was compensated for and serial resistance compensation was switched off. Data were recorded in current clamp (I-clamp), if not stated otherwise, preamplified (Cyberamp380; Axon Instruments), digitized at $10 \mathrm{kHz}$ for voltage and $5 \mathrm{kHz}$ for current, and stored in continuous-stream mode using the CED 1401plus (Cambridge Electronic Design, Cambridge, UK). Electrophysiological data analysis was performed in Spike2 (Cambridge Electronic Design), Origin version 6.0 (Microcal, Southampton, MA), and Excel (Microsoft, Seattle, WA). All membrane potential values were corrected for K-gluconate liquid junction potential (Neher, 1992)

Striatal spiny projection neurons were identified by a spherical soma size of 10-12 $\mu \mathrm{m}$ diameter using Hoffmann modulation contrast optics $(40 \times)$. A Fura-2 fluorescent image, taken 5-10 min after break-in, was used to further identify spiny projection neurons based on the presence of dendritic spines. Neurons were accepted for recordings if (1) the resting membrane potential was more negative than $-75 \mathrm{mV}$, (2) suprathreshold current pulse injection resulted in a ramp-like depolarization that delayed action potential discharge by several hundreds of milliseconds, and (3) neurons could fire action potentials repetitively up to $50 \mathrm{~Hz}$.

For tetrodotoxin (TTX) experiments in voltage clamp ( $V$-clamp), a command voltage protocol was designed that mimicked a somatic depolarization-induced action potential burst from a holding potential of $-80 \mathrm{mV}$ stepped to $-50 \mathrm{mV}$ for $500 \mathrm{msec}$ and five action potentials spaced at $100 \mathrm{msec}$ (temporal resolution, $0.01 \mathrm{msec}$ ). The action potential command voltage trajectory was obtained from averages of 100 action potentials taken from 10 spiny projection neurons.

Fluorescence measurement. Neurons were loaded with the calciumsensitive indicator dye Fura-2 $(100 \mu \mathrm{M})$ via the patch pipette. After break in, the filling was monitored with a $60 \times$ water immersion objective $(1.2$ numerical aperture; working distance, $260 \mu \mathrm{m}$; Olympus Optical) and the neuron was scanned for dendrites within the horizontal plane of interest. Usually one to two primary dendrites and corresponding higherorder dendrites were analyzed simultaneously. Fluorescence measurements were started 10-15 min after break in (Helmchen et al., 1996).

Dye excitation was achieved with a polychromatic illumination system coupled to the microscope via a quartz light guide and wavelength selection via diffraction grating $(12 \mathrm{~nm}$ bandwidth; T.I.L.L. Photonics, Munich, Germany). For all experiments, a beam splitter at $400 \mathrm{~nm}$ and a wide long-pass filter at $510 \pm 20 \mathrm{~nm}$ were used (Omega, Brattleboro, VT). Fluorescence measurements were made with a thermoelectrically cooled CCD camera with a 0.5 inch interline transfer chip and on-chip binning of $4 \times 4$ (Imago, $640 \times 480$ pixels; T.I.L.L. Photonics). Images were collected using commercially available software (Tillvision version 3.3.1; T.I.L.L. Photonics) and stored on computer hard-drive.

Definition of regions of interest. An overview picture (1000 msec exposure; $2 \times 2$ binning) was taken at completion of the experiment. Individual regions of interest (ROIs) were grouped into primary, secondary, and tertiary dendrites, with each area defined by dendritic branching points. For tertiary dendrites, ROIs were only taken for segments that were clearly in the plane of focus as well as within the frame of view (average segment length, 10-20 $\mu \mathrm{m}$ ). Background was defined as the area adjacent to each ROI that was located outside the neuron of interest. Calculations for ROIs and associated changes in $\left[\mathrm{Ca}^{2+}\right]_{i}$ were measured with dual-wavelength imaging $(340 / 380 \mathrm{~nm})$ and expressed as a ratio or measured with single-wavelength imaging $(380 \mathrm{~nm})$ and expressed as $\Delta F / F$.

$\Delta \mathrm{F} / \mathrm{F}$ and ratio calculations. $\Delta F / F$ values for ROIs were calculated for each frame as $\left(F_{\mathrm{i}}-F_{0}\right) / F_{0}$ and expressed as percentage of change, where $F_{0}$ indicates the baseline fluorescence obtained from the average of 10-20 frames during the down-state and $F_{\mathrm{i}}$ indicates individual fluorescence measures at frame $i$. Background correction was calculated for each image frame and subtracted from both $F_{\mathrm{i}}$ and $F_{0}$. For ratio imaging, pixel intensities from images taken at $340 \mathrm{~nm}$ were divided by pixel intensities from subsequent images taken at $380 \mathrm{~nm}$ after background subtraction for each ROI. $\Delta F / F_{\max }$ was taken at the time point at which $\Delta F / F$ values reached maximum and was usually within the same frame between ROIs.

$\left[\mathrm{Ca}^{2+}\right]_{i}$ during down-state. $\left[\mathrm{Ca}^{2+}\right]_{\mathrm{i}}$ concentrations were calculated according to the following equation: $\left[\mathrm{Ca}^{2+}\right]_{\mathrm{i}}=K_{\text {eff }} \times\left[\left(R-R_{\min }\right) /\left(R_{\max }-\right.\right.$ $R)$ ], where $R_{\min }$ and $R_{\max }$ are ratio values obtained during the calibration under $0\left[\mathrm{Ca}^{2+}\right]$ and saturating $39.8 \mu \mathrm{M}\left[\mathrm{Ca}^{2+}\right]$ (theoretical saturation for Fura-2), respectively, and $R$ indicates ratio values measured during the recording. All values were corrected for background fluorescence. Calibration was performed at the same temperature as experiments using a Fura-2 calcium-imaging calibration kit ranging from 0 to $10 \mathrm{~mm}$ Ca-EGTA and $50 \mu \mathrm{M}$ Fura-2 (Molecular Probes). A $K_{\mathrm{d}}$ estimated as $185.4 \mathrm{~nm}$ for $36^{\circ} \mathrm{C}$ was used for the calculation of $K_{\mathrm{eff}}$ (Groden et al., 1991).

On-line detection and measurement of spontaneous up-states. Initial attempts to identify up-states by fitting membrane potential distributions with Gaussian functions were abandoned because membrane potentials in successive sample points at $2 \mathrm{msec}$ were not independent (membrane time constant) and membrane potentials were rectified at depolarized (spike threshold) and hyperpolarized (anomalous rectification) levels. Therefore, routines written in assembly language for speed were designed to scan the intracellular membrane potential on-line to detect up-state transitions as well as down-state periods. The detection was based on on-line statistical membrane potential analysis, where a threshold was calculated at $5 \times$ SD during periods of low spontaneous activity. Positive threshold crossing by the membrane potential indicated a transition to the up-state, whereas negative threshold crossing indicated a return to a down-state. Threshold crossings were discarded if the time from positive threshold crossing to negative crossing was $\leq 50 \mathrm{msec}$. On average, cells spent $90 \%$ of their time below threshold.

The amplitude of spontaneous membrane potential fluctuations in the down-state was analyzed off-line. Using a threshold at $2 \mathrm{mV}$ above 
A

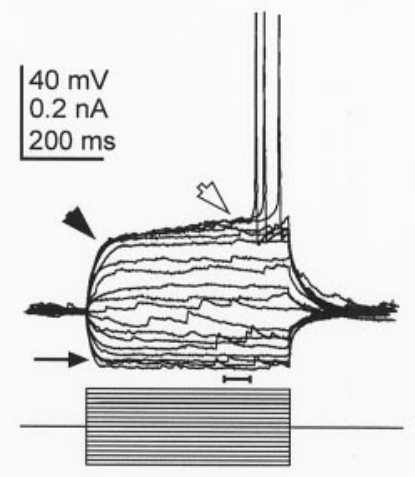

B

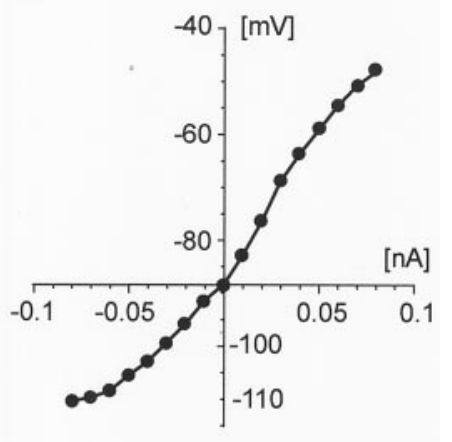

C
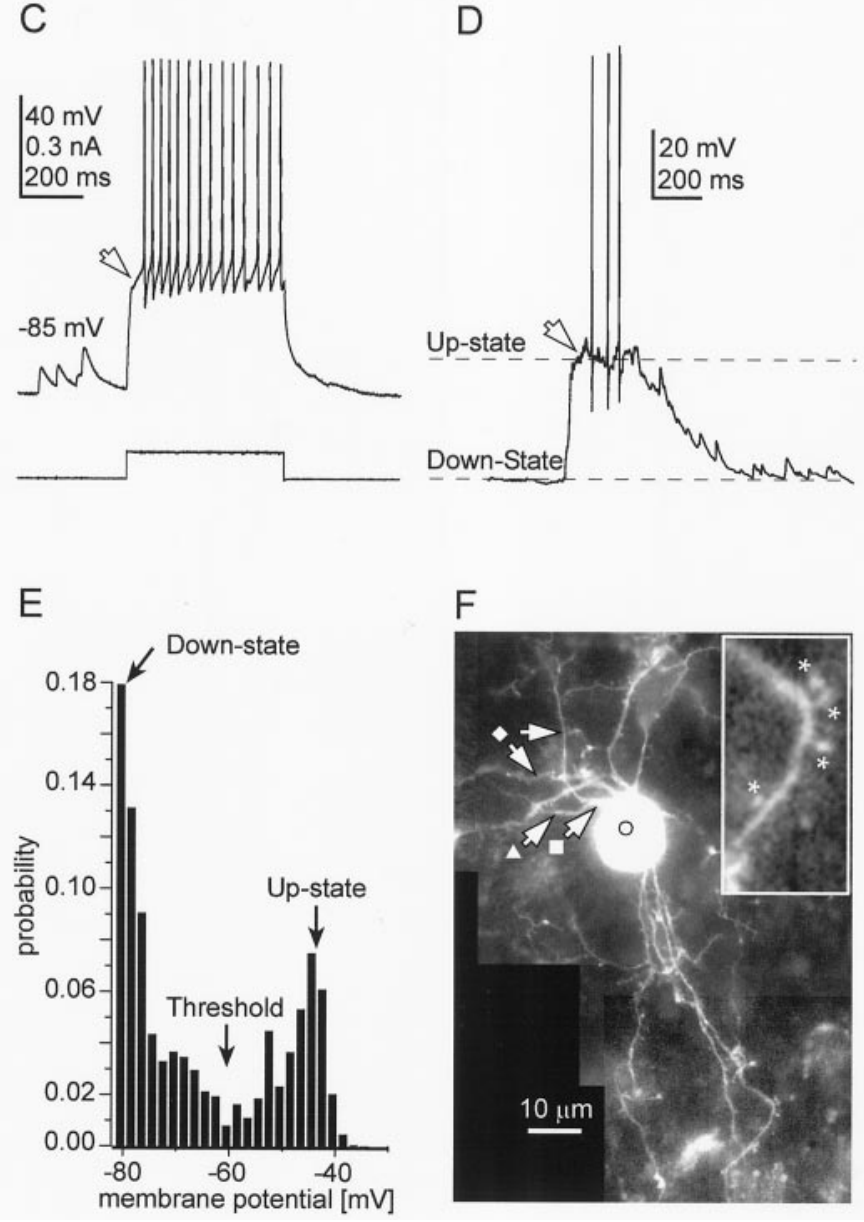

$\mathrm{F}$

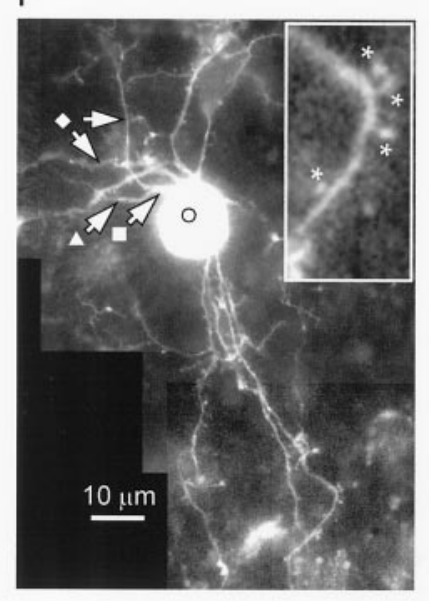

Figure 1. Membrane properties, spontaneous activity, and morphological characteristics of spiny projection neurons recorded in whole-cell patch configuration. $A$, Membrane potential responses to somatic current injections during the down-state are characterized by anomalous rectification at hyperpolarized potentials (arrow), early outward rectification with depolarization (closed arrowhead), ramp-like trajectory toward threshold (open arrowhead), and delayed action potential firing (maximal depolarization pulse repeated 3 times, $15 \mathrm{~min}$ after break in). Note fluctuations indicative of irregular spontaneous synaptic inputs. $B$, Nonlinear steady-state $I-V$ relationship (from the time indicated by the bar in $A$ ). $C$, Characteristic delay in burst firing by somatic current injections (open arrowhead). D, Spontaneous, suprathreshold up-state. Note the fast transition to the upstate, delay in burst firing onset during the up-state (open arrowhead), and relatively slow return to the down-state. $E$, Bimodal membrane potential distribution that reflects the relatively fast transition between down- and up-states. Values were taken from the trace in $D$ at $2 \mathrm{msec}$ time resolution. $F$, Fluorescence image 35 min after break in at $380 \mathrm{~nm}(100 \mu \mathrm{M}$ Fura-2;

average resting value with successive positive peak detection, average amplitudes were calculated for peak-aligned spontaneous events.

Down-state imaging (20-40 frames; 20-40 msec duration each; 380 and $340 \mathrm{~nm}$, respectively) was performed when the cell was in a downstate for at least $1.5 \mathrm{sec}$. This ensured that $\left[\mathrm{Ca}^{2+}\right]_{\mathrm{i}}$ transients from the previous up-state did not bias down-state measurements. After downstate fluorescence measurements, threshold crossing by a spontaneous up-state subsequently triggered up-state measurements. On average, $120-300$ consecutive images $(20-40 \mathrm{msec}$ duration each; $380 \mathrm{~nm}$ or $380 / 340 \mathrm{~nm}$ ) were collected to measure a down-state and subsequent up-state. To exclude possible additive effects of $\left[\mathrm{Ca}^{2+}\right]_{\mathrm{i}}$ transients, upstates that occurred closer than $1.5 \mathrm{sec}$ to a preceding negative threshold crossing were not included in the analysis.

Measurement of fluorescence change during current injection. Responses during the down-state were measured at least $1.5 \mathrm{sec}$ after return from an up-state. One to 10 pulses of depolarizing current injection $(500 \mathrm{msec})$ were given at increasing steps (0.01 nA minimum; 0.01-0.02 nA step size), resulting in subthreshold or both subthreshold and suprathreshold responses. Either a sequence of images was taken for a single current pulse (10 images of 380 and $340 \mathrm{~nm}$ for $F_{0}$ and 50 images of 380 and 340 nm for $F_{\mathrm{i}}$ ) or a continuous sequence of images was taken for multiple current pulses (10 images of 380 and $340 \mathrm{~nm}$ for $F_{0}$ and 150 images of 380 and $340 \mathrm{~nm}$ for $F_{\mathrm{i}}$ ). Because of the strong effect of the A-current after depolarization in spiny projection neurons, $\Delta F / F_{\max }$ values for subthreshold membrane depolarizations were usually taken from the last frame during the current pulse and compared with average $\Delta F / F_{\max }$ values taken before current injection.

Dye concentration, bleaching, resting base line, drug application. Initial experiments using different concentrations of Fura-2 revealed that Fura- 2 concentrations of $>100 \mu \mathrm{M}$ severely interfered with the internal calcium dynamics (Neher and Augustine, 1992) and were detrimental during repetitive action potential firing. A concentration of $100 \mu \mathrm{M}$ allowed recording for at least $25 \mathrm{~min}$, did not significantly change action potential width, and allowed single-sweep optical recordings from secondary and tertiary dendrites. Frames taken at the beginning and end of the imaging period near the isofluoremetric point of Fura-2 $(358 \mathrm{~nm})$ were used to monitor dye bleaching. Data were rejected if dye bleaching exceeded the average baseline fluctuations during the imaging period. TTX (1 $\mu \mathrm{m}$; Sigma) was dissolved to final concentration in gassed recording solution and bath applied.

Data are expressed as mean \pm SEM. For statistical data analysis, ANOVA with Scheffé's post hoc test was used unless stated otherwise. Correlation and partial correlation was estimated by linear regression analysis (StatView; SAS Institute, Inc., Cary, NC).

\section{RESULTS}

\section{Membrane properties and spontaneous up-states of cultured spiny projection neurons recorded in whole-cell patch configuration}

Spiny projection neurons $(n=55)$ showed a polarized resting membrane potential of $-82.5 \pm 0.9 \mathrm{mV}$ and neurons displayed inward and outward rectification as well as delayed action potential firing in response to somatic current injections (Fig. 1 $A-C$ ). Their spontaneous activity in cortex-striatum-substantia nigra cultures was characterized by irregular up-states with delayed bursts of action potentials separated by down-states, as described previously (Fig. 1D) (Plenz and Kitai, 1998). In the present study, up-states lasted on average for $1.28 \pm 0.10 \mathrm{sec}$ and occurred irregularly at an average interval of $11.7 \pm 1.4 \mathrm{sec}(n=10$ neurons; 10 up-states per neuron). During up-states, spiny projection neurons were depolarized by $38.8 \pm 1.0 \mathrm{mV}$ to reach threshold $(n=40)$. In the down-state, the spontaneous membrane potential trajectory was characterized by numerous depolarizations with an average peak value of $4.3 \pm 1.3 \mathrm{mV}$ (Figs. 1 $A, 2 A$ )

$1 \mathrm{sec}$ exposure; composite from 9 individual images). Circle, Soma; square, primary dendrites; triangle, secondary dendrites; diamond, tertiary dendrites. Note spines on dendrites (inset, asterisks). 


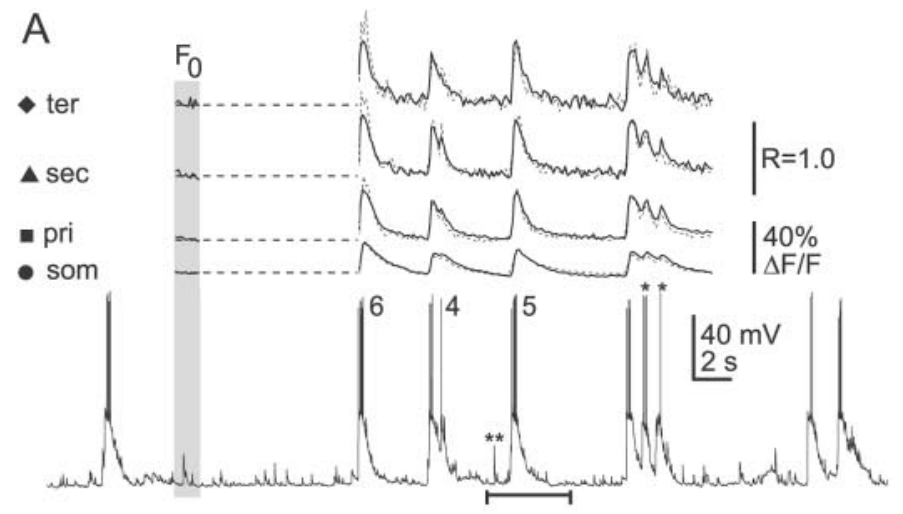

B
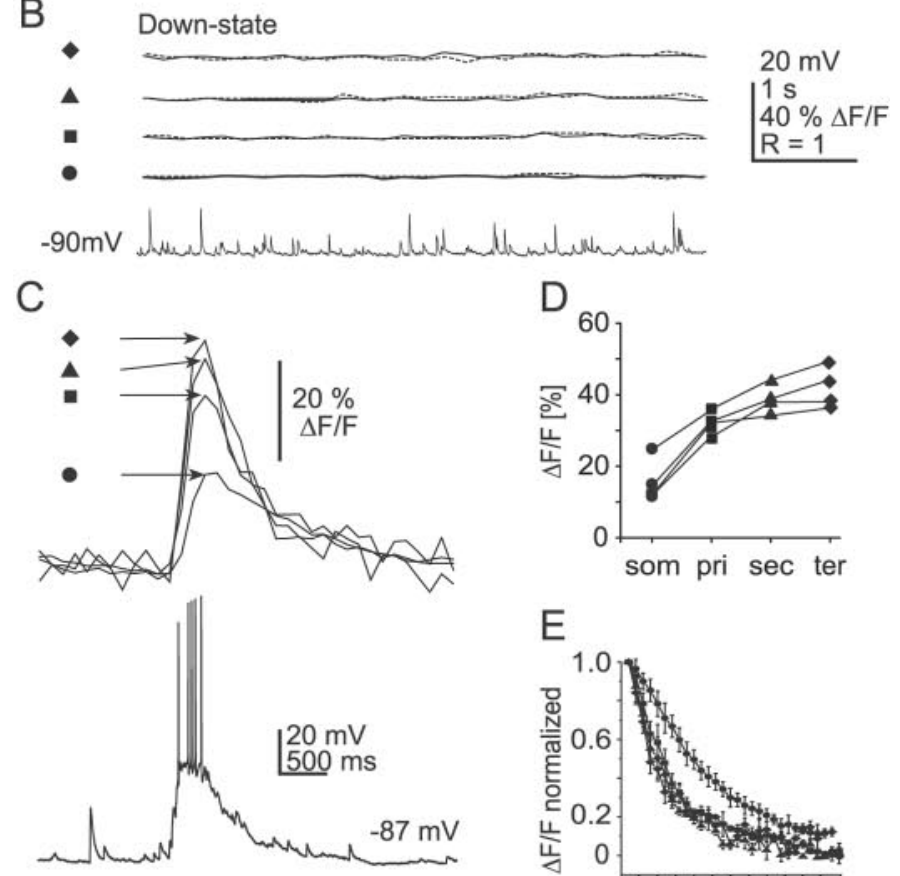

E

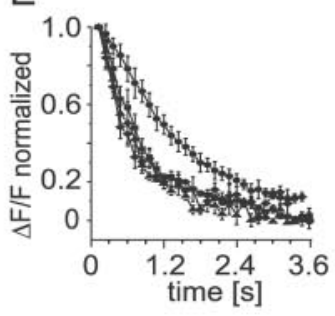

$\mathrm{F}$
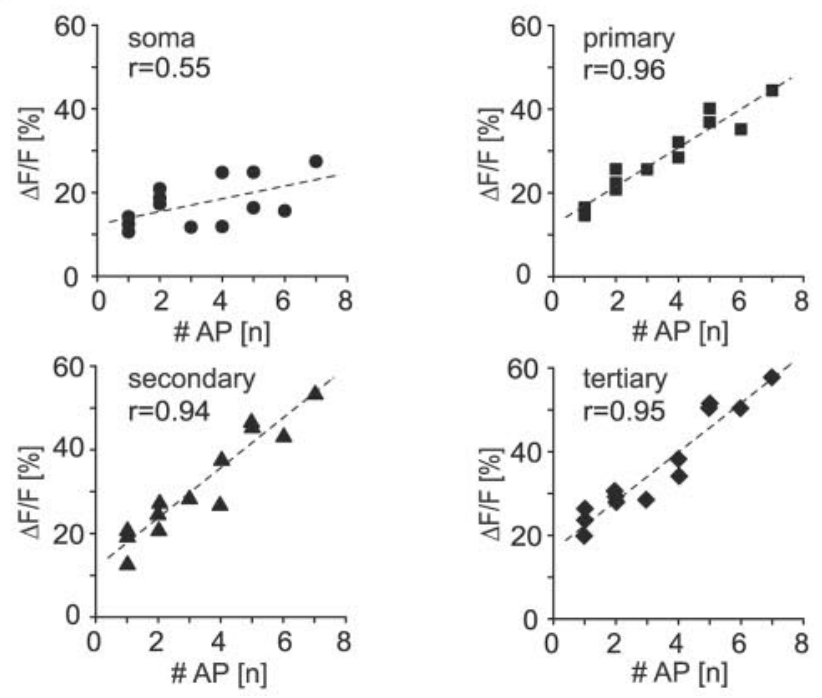

Figure 2. Spontaneous up-states in spiny projection neurons correlate with large $\left[\mathrm{Ca}^{2+}\right]_{\mathrm{i}}$ transients in soma and dendrites. $A$, Simultaneous, single-sweep measurement of $\left[\mathrm{Ca}^{2+}\right]_{\mathrm{i}}$ transients in soma and dendrites (upper traces) and corresponding spontaneous intracellular membrane potential activity at the soma (bottom trace). $F_{0}$ values were taken during
(1 sec per neuron; $n=10$ neurons). Peak depolarizations during down-states were significantly smaller compared with depolarizations reached during up-states $(p<0.0001)$. Transitions between up- and down-states were relatively fast, resulting in bimodal membrane potential distributions (Fig. $1 E$ ). Dye-loading with Fura-2 $(100 \mu \mathrm{M})$ during the recording also allowed for identification of spiny projection neurons based on their spherical soma and spiny higher-order dendrites (Fig. $1 F$ ). Action potential threshold, amplitude, width, slopes, and afterhyperpolarization did not significantly differ for both evoked and spontaneous conditions (Table 1).

\section{Up-states correlate with large $\left[\mathrm{Ca}^{2+}\right]_{i}$ transients in soma and dendrites}

The time course and spatial distribution of $\left[\mathrm{Ca}^{2+}\right]_{i}$ transients during spontaneous up-states in spiny projection neurons was addressed by simultaneously measuring somatic and dendritic $\left[\mathrm{Ca}^{2+}\right]_{\mathrm{i}}$ transients as well as somatic membrane potential during spontaneous activity (Fig. $2 A-C$ ).

$\left[\mathrm{Ca}^{2+}\right]_{\mathrm{i}}$ transients followed the overall time course of the somatic membrane potential (Fig. $2 A$ ) when analyzed using either dual-wavelength comparison (ratiometric, $340 / 380 \mathrm{~nm}$ ) or single wavelength ( $380 \mathrm{~nm}$, relative percentage change as $\Delta F / F$ ). Thus, for reasons of higher time resolution, most experiments were performed using single-wavelength $\Delta F / F$.

At the single-neuron level, the spatial distribution of $\Delta F / F$ transients during individual up-states showed two characteristics. First, dendritic $\Delta F / F$ transients reached higher $\Delta F / F_{\max }$ values when compared with soma ( $p<0.001 ; n=21)$, and second, dendritic $\Delta F / F_{\max }$ values tended to increase from primary to tertiary dendrites, regardless of the absolute $\Delta F / F_{\max }$ reached within each compartment (Fig. $2 C, D$ ). These relations in $\Delta F / F_{\text {max }}$ for soma and dendrites during up-states were also present at the population level (see Fig. $4 A$ ). Across neurons, $\Delta F / F_{\max }$ at the soma was significantly lower than in dendrites $(p<0.001)$ and $\Delta F / F_{\text {max }}$ values increased from primary to tertiary dendrites (see Fig. $4 A$ ) (two to three up-states per neuron; $n=21$ neurons). During down-states, both $\Delta F / F$ and ratio values were stable in soma as well as in dendrites; $\left[\mathrm{Ca}^{2+}\right]_{\mathrm{i}}$ was estimated to range between 30 and $60 \mathrm{~nm}$ in soma and primary dendrites (Fig. 2B) ( $n=4$ neurons).

a period in the down-state indicated by the leftmost segments (shaded; 20 frames). Frames were collected at 340 and $380 \mathrm{~nm}$ wavelength ( $\Delta 42 \mathrm{msec}$ each), allowing background corrected calculation of both ratio $(\Delta 120$ msec; dotted lines) and $\Delta F / F$ values $(380 \mathrm{~nm} ; \Delta 120 \mathrm{msec}$; solid lines $)$. Note the similar time course of estimated $\left[\mathrm{Ca}^{2+}\right]_{\mathrm{i}}$ transients with both methods. Measurements were arbitrarily scaled to first soma peak values, respectively, to facilitate comparison. Up-states that occurred within $1.5 \mathrm{sec}$ of previous up-states $(*)$ and depolarizations above threshold for $<50 \mathrm{msec}$ $(* *)$ were discarded from analysis. Numbers of action potentials are indicated for each up-state. Circle, Soma; square, primary dendrites; triangle, secondary dendrites; diamond, tertiary dendrites. $B$, Changes in somatic and dendritic $\Delta F / F$ are small during the down-state when compared with up-state periods (340 and $380 \mathrm{~nm} ; \Delta 62 \mathrm{msec}$ each). $C$, Relationship between $\Delta F / F_{\max }$ values during up-states at higher temporal resolution (taken from $A$, bar). $D$, Summary of $\Delta F / F_{\max }$ values for the first four up-states shown in $A$. $E$, Averaged normalized decay from $\Delta F / F_{\max }$ for each region (3 neurons; 3-4 up-states each). Note the slower time course at soma compared with dendrites. $F$, Dendritic $\Delta F / F_{\max }$ values and the number of somatic action potentials are linearly correlated during spontaneous up-states (same neuron as in $A$ ). Dashed lines indicate regression functions for each compartment. 
Table 1. Spontaneous action potentials during up-states are similar to action potentials elicited by somatic current injection (I-clamp, whole-cell patch configuration including $100 \mu \mathrm{M}$ Fura-2; $n=40$ neurons)

\begin{tabular}{|c|c|c|c|c|c|c|c|c|c|}
\hline & $\begin{array}{l}\text { Time } \\
(\mathrm{sec})\end{array}$ & $\begin{array}{l}\text { Threshold } \\
(\mathrm{mV})\end{array}$ & $\begin{array}{l}\operatorname{Max} \\
(\mathrm{mV})\end{array}$ & $\begin{array}{l}\text { Amplitude } \\
(\mathrm{mV})\end{array}$ & $\begin{array}{l}\text { Width } \\
\text { (msec) }\end{array}$ & $\begin{array}{l}+\mathrm{dV} / \mathrm{dt} \\
(\mathrm{V} / \mathrm{sec})\end{array}$ & $\begin{array}{l}-\mathrm{dV} / \mathrm{dt} \\
(\mathrm{V} / \mathrm{sec})\end{array}$ & $\begin{array}{l}\text { Slope } \\
\text { ratio }\end{array}$ & $\begin{array}{l}\mathrm{AHP}_{\text {max }} \\
(\mathrm{mV})\end{array}$ \\
\hline Up-s & $504 \pm 98$ & $-45 \pm 1.5$ & $31 \pm 2.7$ & $75 \pm 2.1$ & $1.28 \pm 0.1$ & $134 \pm 8.93$ & $56 \pm 4$ & $2.4 \pm 0.1$ & $9 \pm 1$ \\
\hline Current injection & $524 \pm 123$ & $-43 \pm 1.4$ & $32 \pm 2.7$ & $76 \pm 2.1$ & $1.20 \pm 0.1$ & $137 \pm 9$ & $53 \pm 4$ & $2.6 \pm 0.1$ & $15 \pm 3$ \\
\hline
\end{tabular}

Time, Time of measurement after break in. Action potential parameters and significance: threshold, $p=0.336$; absolute maximum (max), $p=0.795$; amplitude, $p=0.738$; half width (width), $p=0.575$; positive/negative maximal slope $( \pm \mathrm{dV} / \mathrm{dt}), p=0.814,0.599$; ratio between positive and negative slope (slope ratio), $p=0.165$; afterhyperpolarization $\left(\mathrm{AHP}_{\max }\right), p=0.067$. Values are mean $\pm \mathrm{SEM}$
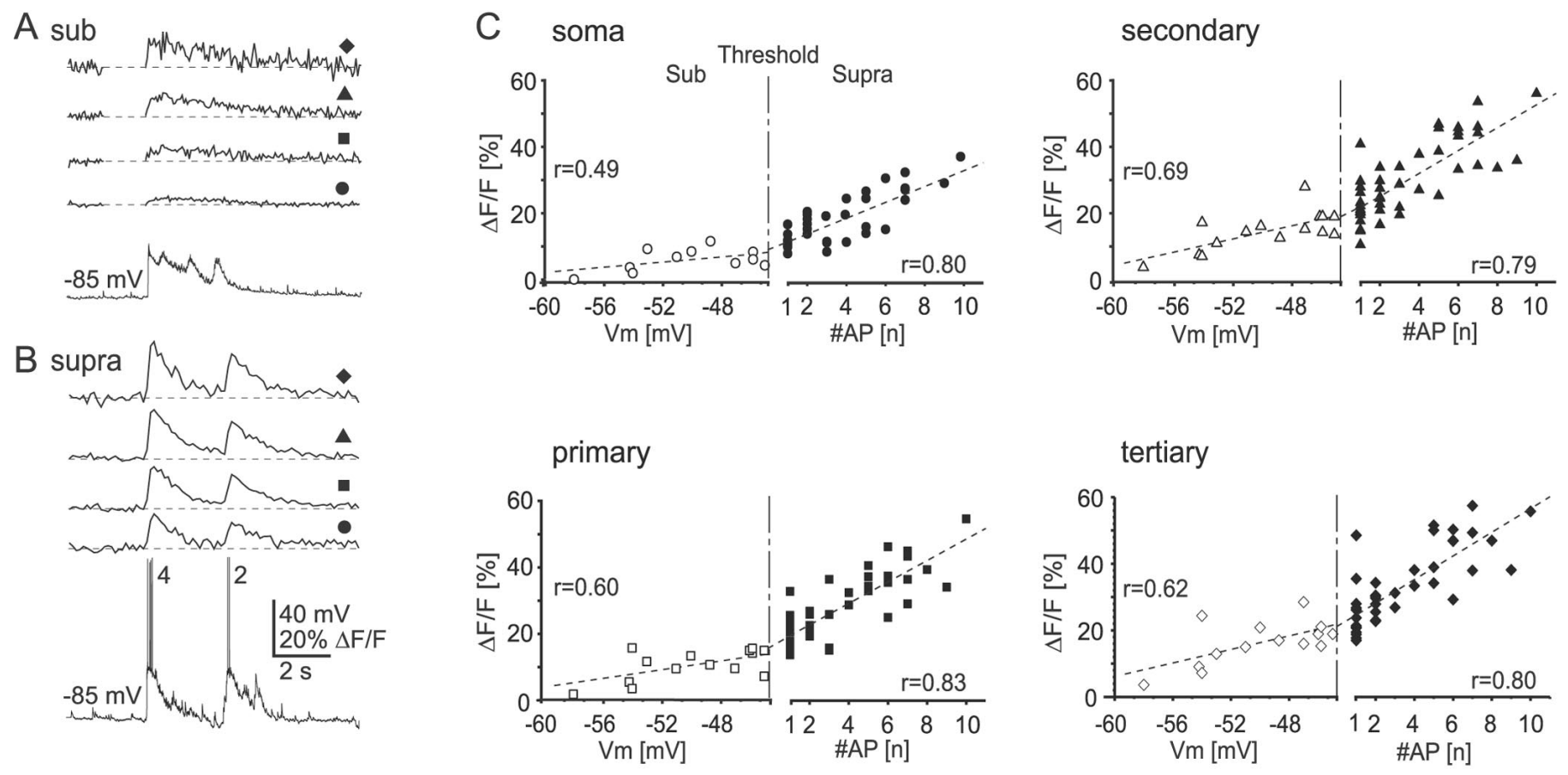

Figure 3. Dynamic range of $\Delta F / F_{\max }$ values reveals linear correlation within and continuity between subthreshold and suprathreshold up-states. Circle, Soma; square, primary dendrites; triangle, secondary dendrites; diamond, tertiary dendrites. $A$, Time course of $\Delta F / F$ during subthreshold up-states. Note the increase in $\Delta F / F_{\max }$ from soma to higher-order dendrites. $B, \Delta F / F_{\max }$ values in suprathreshold up-states are correlated with the number of spontaneous somatic action potentials. Note the similar overall time course of up-states but different number of action potentials (4 and 2 , respectively). $C, \Delta F / F_{\max }$ values continuously encode the transition from subthreshold to suprathreshold up-states. $L e f t, \Delta F / F_{\max }$ values are linearly correlated with peak membrane potential depolarization during subthreshold up-states (open symbols). Right, $\Delta F / F_{\max }$ values are linearly correlated with the number of spontaneous action potentials during suprathreshold up-states (closed symbols). Center, Broken vertical lines indicate a population action potential threshold of $-44.7 \mathrm{mV}$ aligned to 0 action potentials. Linear regression is indicated by dashed lines.

The time course in $\Delta F / F$ during the return to the down-state was relatively uniform and was analyzed by fitting a single exponential function to the decay from normalized $\Delta F / F_{\max }$ values (Fig. $2 E)(r=0.92-0.99$; three to four up-states per neuron; $n=$ 3 neurons). Dendritic decay in $\Delta F / F$ revealed a single time constant of $790 \pm 10 \mathrm{msec}$ that was not different between dendritic compartments ( $p=0.518-0.953)$. In contrast, the somatic decay of $\left[\mathrm{Ca}^{2+}\right]_{\mathrm{i}}$ transients had a time constant of $1100 \pm 40 \mathrm{msec}$, which was significantly slower when compared with dendrites $(p<0.0001)$.

In neurons that showed a wide range in the number of spontaneous action potentials during up-states, a surprisingly high correlation, particularly in dendrites, was revealed when plotting spontaneous action potential number against $\Delta F / F_{\max }$ (Fig. $2 F$ ) $(r=0.97 \pm 0.01$; two to eight action potentials; $n=3$ neurons). This correlation was also present at the population level (Fig. 3C) ( $r=0.79-0.83 ; n=21$ neurons; three to four up-states per neuron). Average slope values in $\Delta F / F_{\max }$ ranged from $24 \pm 3 \%$ to $36 \pm 4 \%$ per 10 action potentials and were similar in dendrites but significantly lower at the soma (Fig. $3 C)(p<0.001 ; n=21$ neurons).

To summarize, up-states in spiny projection neurons were correlated with large $\left[\mathrm{Ca}^{2+}\right]_{\mathrm{i}}$ transients that decayed within $1 \mathrm{sec}$ after reaching maximum. The corresponding $\Delta F / F_{\max }$ values were highly correlated with the total number of spontaneous action potentials during the up-state.

\section{Dendritic $\left[\mathrm{Ca}^{2+}\right]_{\mathrm{i}}$ continuously encodes subthreshold and suprathreshold activity during up-states}

To discriminate between effects of synaptic activity and somatic action potential firing on $\left[\mathrm{Ca}^{2+}\right]_{i}$ transients, subthreshold upstates were compared with suprathreshold up-states.

In the absence of action potentials, prominent $\left[\mathrm{Ca}^{2+}\right]_{\mathrm{i}}$ transients were visible during up-states in both soma and dendrites (Fig. $3 A$ ) and $\Delta F / F_{\max }$ modestly correlated with membrane potential peak values for all regions (Fig. $3 C)(r=0.49-0.69 ; n=10$ neurons; one to two up-states per neuron). Within the up-state 

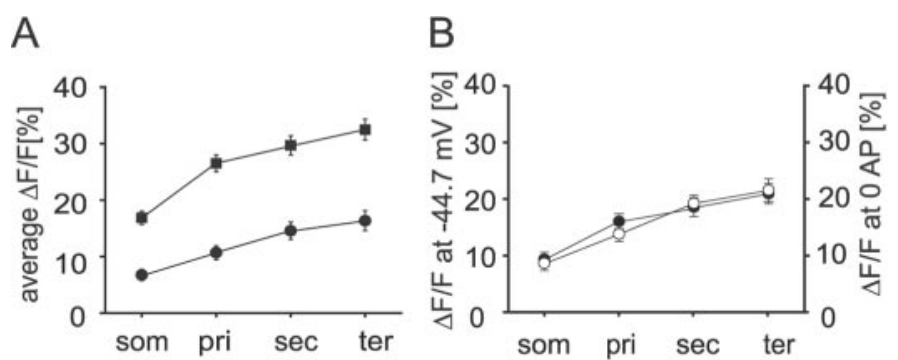

Figure 4. Summary of the dynamic range in $\Delta F / F_{\text {max }}$ during up-states. $A$, Average $\Delta F / F_{\max }$ values were two to three times higher during suprathreshold up-states compared with subthreshold up-states. $B,\left[\mathrm{Ca}^{2+}\right]_{\mathrm{i}}$ transients continuously encoded the transition from subthreshold to suprathreshold up-states in soma and dendrites. Values are based on regression functions (mean $\pm 95 \%$ confidence interval) derived from subthreshold (open circles) and suprathreshold (closed circles) up-states extrapolated to membrane potential threshold and 0 action potentials, respectively.

membrane potential range of -60 to $-45 \mathrm{mV}, \Delta F / F_{\max }$ changed between 0 and $20 \%$, resulting in an average slope of $4 \pm 2 \%$ to $10 \pm 4 \% \Delta F / F_{\max }$ per $10 \mathrm{mV}$ that was not significantly different between compartments (Fig. $3 C$ ) ( $p<0.52 ; n=10$ neurons). Similar to suprathreshold up-states, average $\Delta F / F_{\max }$ values during subthreshold up-states increased toward higher-order dendrites (Fig. 4A).

However, average $\Delta F / F_{\max }$ values during subthreshold upstates were significantly lower compared with suprathreshold upstates (Fig. $4 A, p<0.0001$ ), which raised the question of whether $\left[\mathrm{Ca}^{2+}\right]_{\mathrm{i}}$ transients show a discontinuity at the transition from subthreshold to suprathreshold up-states. Therefore, we predicted $\Delta F / F_{\max }$ values at this transition based on regression functions. Linear regressions based on subthreshold up-state membrane potential values or suprathreshold up-states predicted increasing $\Delta F / F_{\max }$ values from 10 to $20 \%$ (soma to higher-order dendrites) at $-44.7 \pm 1.5 \mathrm{mV}$ (population action potential threshold) or when extrapolated to 0 action potentials, respectively (Fig. $4 B)$. Both predictions highly overlapped for each compartment $(p=0.3-0.84)$.

Thus, $\left[\mathrm{Ca}^{2+}\right]_{\mathrm{i}}$ transients were two to three times smaller during subthreshold up-states compared with suprathreshold up-states. Nevertheless, $\left[\mathrm{Ca}^{2+}\right]_{i}$ transients continuously encoded excitation in spiny projection neurons despite a qualitative discontinuity when moving from subthreshold to suprathreshold up-states.

\section{Action potentials elicit $\left[\mathrm{Ca}^{2+}\right]_{\mathrm{i}}$ transients in higher- order dendrites}

Continuous encoding of $\left[\mathrm{Ca}^{2+}\right]_{\mathrm{i}}$ transients during subthreshold and suprathreshold up-states could simply reflect the dependency of $\left[\mathrm{Ca}^{2+}\right]_{\mathrm{i}}$ on synaptic inputs (Regehr and Tank, 1994). In this view, a rise in synaptic inputs will increase dendritic $\left[\mathrm{Ca}^{2+}\right]_{\mathrm{i}}$ as well as trigger more action potentials, resulting in a correlation between action potential number and $\left[\mathrm{Ca}^{2+}\right]_{\mathrm{i}}$. Alternatively, action potentials could directly contribute to dendritic $\left[\mathrm{Ca}^{2+}\right]_{\mathrm{i}}$ by propagating along dendrites (Häusser et al., 2000). Dendritic $\left[\mathrm{Ca}^{2+}\right]_{\mathrm{i}}$ transients were therefore measured during repetitive bursts of action potentials evoked by somatic current injections during the down-state (Fig. 5).

Action potentials from suprathreshold current injection evoked large $\left[\mathrm{Ca}^{2+}\right]_{\mathrm{i}}$ transients at soma and primary, secondary, and tertiary dendrites (Fig. 5A,B). At a fixed burst strength (i.e., number of action potentials per $500 \mathrm{msec})$, these $\left[\mathrm{Ca}^{2+}\right]_{\mathrm{i}}$ transients were reliably elicited and did not change over the period of multiple bursts, resulting in stereotypical transients throughout the neuron (Fig. $5 B$ ). The $\Delta F / F$ time course during each burst revealed a fast onset that was correlated with the first action potential (Fig. $5 C$ ). At burst termination, the decay from $\Delta F / F_{\text {max }}$ was fitted by a single exponential decay $(r=0.97-0.99$; soma to tertiary dendrites; $n=4$ neurons). On average, dendritic $\left[\mathrm{Ca}^{2+}\right]_{\mathrm{i}}$ transients decayed to $37 \%$ within $504 \pm 12 \mathrm{msec}$ after burst termination, which was faster compared with the somatic $\left[\mathrm{Ca}^{2+}\right]_{\mathrm{i}}$ decay $(p<0.002)$ and dendritic $\left[\mathrm{Ca}^{2+}\right]_{\mathrm{i}}$ decay during up-states (Fig. $5 D)(p<0.0001)$.

To test whether evoked $\left[\mathrm{Ca}^{2+}\right]_{i}$ transients encode somatic subthreshold membrane potential and burst strength, current pulses of $500 \mathrm{msec}$ duration at varying amplitudes were applied during down-states (Fig. 6) ( $n=12$ neurons). Subthreshold depolarizations evoked small but significant $\left[\mathrm{Ca}^{2+}\right]_{\mathrm{i}}$ transients at soma $\left(4.82 \pm 0.60 \% \Delta F / F_{\max } ; p<0.0001\right)$ and primary dendrites $\left(3.58 \pm 0.46 \% \Delta F / F_{\text {max }} ; p<0.01\right)($ Fig. $6 B-D)$. However, they did not elicit $\left[\mathrm{Ca}^{2+}\right]_{\mathrm{i}}$ transients at higher-order dendrites $(p=0.100$ and $p=0.255$, respectively). Thus, $\Delta F / F_{\max }$ values during subthreshold somatic depolarizations were significantly lower in all dendritic compartments when compared with $\Delta F / F_{\max }$ values from subthreshold up-states $(p<0.0001)$, despite covering a similar voltage range for both conditions (current injection, $-50 \pm 1 \mathrm{mV}$; range, -58 to $-55 \mathrm{mV}$; up-state, $-55 \pm 2 \mathrm{mV}$; range, -60 to $-43 \mathrm{mV}$ ). No difference was found for both conditions in somatic $\Delta F / F_{\max }$ values $(p=0.61)$.

In contrast, suprathreshold current injections resulted in $\Delta F / F_{\max }$ values throughout the dendritic arbor that were highly correlated with the number of action potentials across all neurons examined (Fig. 6B,C) $(r=0.83-0.86 ; y=a+b \times x ; n=26$ neurons). This correlation was not improved when using a simple saturation function $\left[r=0.81-0.84 ; y=a \times\left(1-\mathrm{e}^{-\mathrm{bx}}\right)\right]$. Within the range of $1-20$ action potentials per $500 \mathrm{msec}$ duration, $\Delta F / F_{\max }$ increased by $14 \pm 1 \%$ to $16 \pm 2 \% \Delta F / F_{\max }$ per 10 action potentials for all compartments. This slope was significantly lower when compared with suprathreshold up-states ( $p<0.005$, soma and dendrites). Average $\Delta F / F_{\max }$ values during suprathreshold current injections were relatively high in soma and dendrites (27-33\%) and were not significantly different between dendrites $(p=0.22-0.66)$, but were significantly higher compared with $\Delta F / F_{\max }$ during subthreshold depolarizations $(p<0.001)$ (Fig. 6D).

To understand the dynamic range of $\left[\mathrm{Ca}^{2+}\right]_{\mathrm{i}}$ transients at the transition from subthreshold to suprathreshold somatic current injection, $\Delta F / F_{\max }$ values at this transition were predicted based on regression functions. Based on membrane potentials during subthreshold down-states, decreasing $\Delta F / F_{\max }$ values from 7 to $3 \%$ (soma to higher-order dendrites) were predicted at a membrane potential threshold of $-44.7 \pm 1.5 \mathrm{mV}$. In contrast, $\Delta F / F_{\max }$ values of between 12 and $16 \%$ (soma to higher-order dendrites) were predicted when based on action potentials during suprathreshold current injections and extrapolated to 0 action potentials (Fig. 6E). Both predictions were significantly different for each compartment, respectively ( $p<0.001$ ) (Fig. $6 E$ ).

To summarize, subthreshold somatic depolarization by current injection only elicited $\left[\mathrm{Ca}^{2+}\right]_{i}$ transients at the soma, which is markedly different compared with subthreshold upstates. However, somatic action potentials temporarily raised intracellular $\left[\mathrm{Ca}^{2+}\right]_{\mathrm{i}}$ throughout the dendritic arbor of spiny projection neurons. These $\left[\mathrm{Ca}^{2+}\right]_{\mathrm{i}}$ transients were highly cor- 


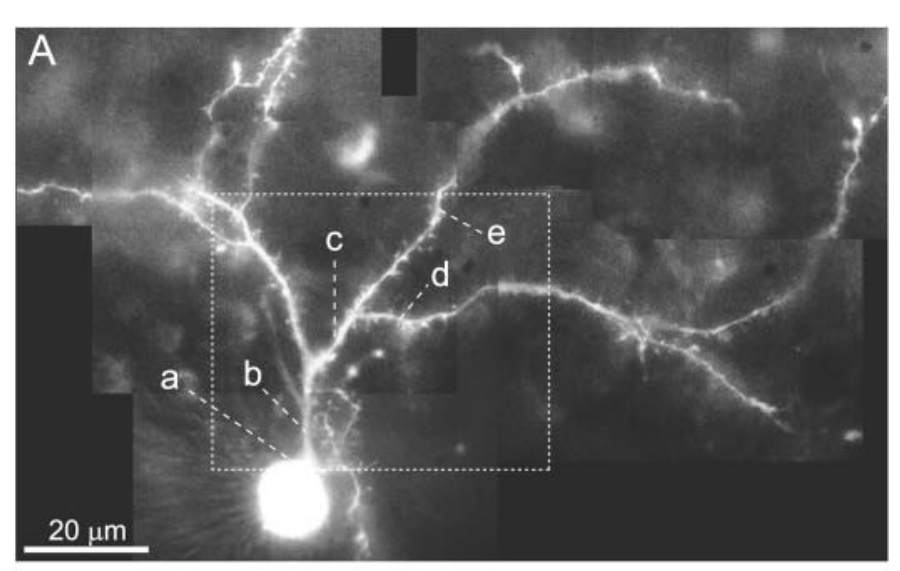

B
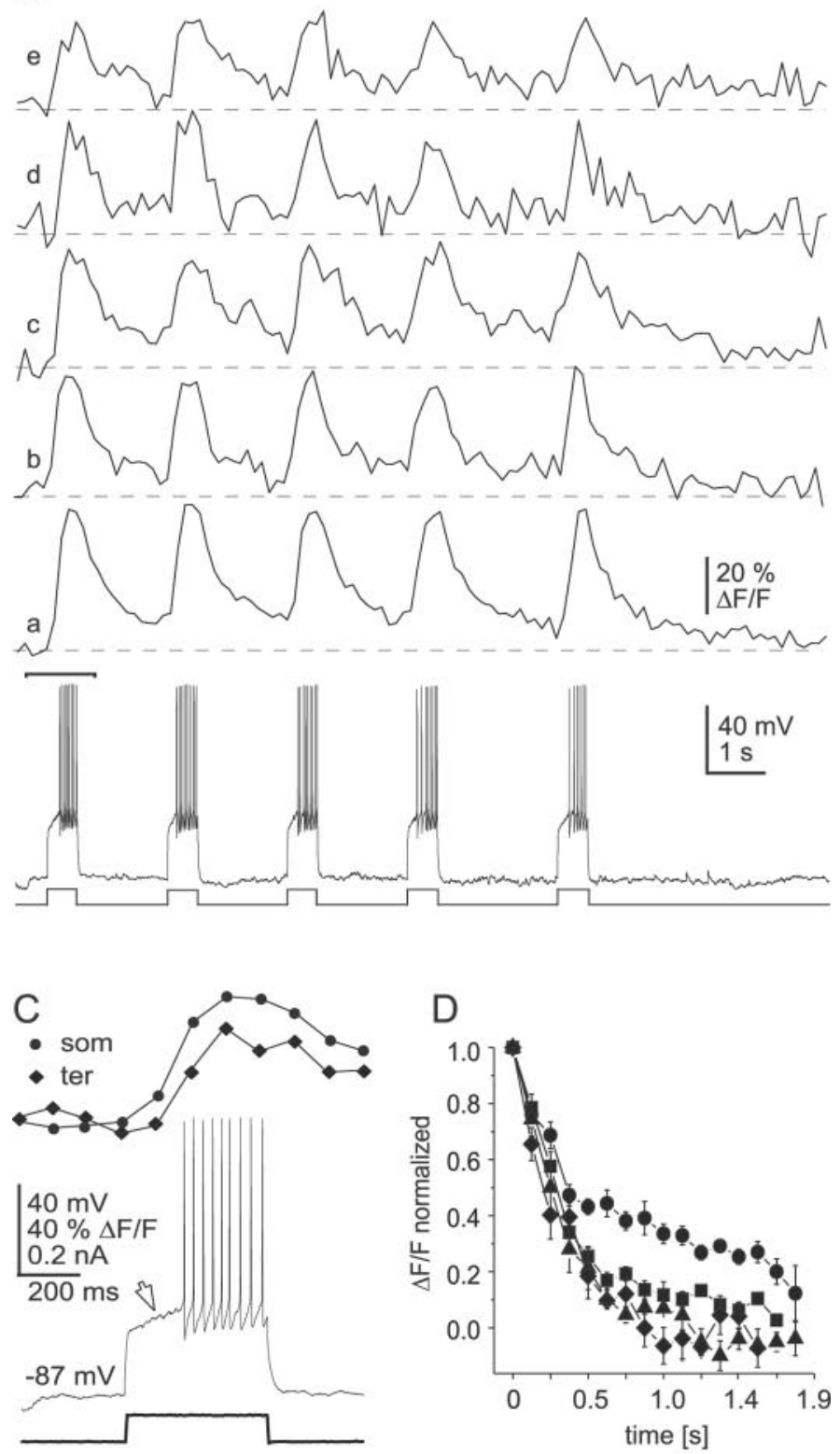

Figure 5. Action potentials elicit stereotypical $\left[\mathrm{Ca}^{2+}\right]_{\mathrm{i}}$ transients in higher-order dendrites during the down-state. $A$, Composite fluorescence image of the spiny projection neuron (Fura-2; $1 \mathrm{sec}$ exposure at $380 \mathrm{~nm}$; 40 min after break in). Dashed lines indicate centers of ROIs located within the optical field of view (dotted box). B, Repetitive burst discharge related with somatic burst strength (i.e., number of action potentials per $500 \mathrm{msec}$ ), which is similar to suprathreshold up-states.

\section{Somatic action potentials elicit dendritic $\left[\mathrm{Ca}^{2+}\right]_{\mathrm{i}}$ transients by active propagation along dendrites during the down-state}

Somatic action potentials have been shown to actively backpropagate and elicit $\left[\mathrm{Ca}^{2+}\right]_{\mathrm{i}}$ transients in higher-order dendrites (Stuart and Sakmann, 1994; Stuart et al., 1997b; Häusser et al., 2000). However, for neurons with relatively short dendrites, such as striatal spiny projection neurons, passive propagation might be sufficient, assuming standard cable properties (Turner, 1984). Alternatively, spiny projection neurons might be highly shunted at soma and dendrites, which would require the presence of dendritic sodium channels for action potentials to propagate and elicit $\left[\mathrm{Ca}^{2+}\right]_{\mathrm{i}}$ transients throughout the dendritic tree.

Dendritic $\left[\mathrm{Ca}^{2+}\right]_{\mathrm{i}}$ transients were first measured in response to somatic suprathreshold current injections (Fig. 7) $(n=3)$. Next, the sodium channel blocker TTX $(1 \mu \mathrm{M})$ was bath applied and recording was switched to $V$-clamp. Voltage commands were applied that forced the somatic membrane potential through a similar trajectory to bursts recorded in I-clamp with suprathreshold depolarizing current (Fig. 7E,F). In the presence of TTX, spontaneous activity was abolished and somatic current pulses that were suprathreshold under control conditions increased $\left[\mathrm{Ca}^{2+}\right]_{\mathrm{i}}$ in the soma but not in higher-order dendrites (Fig. 7C). After switching to $V$-clamp, burst-like voltage commands increased $\left[\mathrm{Ca}^{2+}\right]_{\mathrm{i}}$ at the soma but failed to elicit $\left[\mathrm{Ca}^{2+}\right]_{\mathrm{i}}$ transients at distal dendrites (Fig. 7D,G). No significant difference was found in somatic $\left[\mathrm{Ca}^{2+}\right]_{\mathrm{i}}$ between both conditions (Fig. $\left.7 G\right)(p=$ 0.883). Dendritic $\left[\mathrm{Ca}^{2+}\right]_{\mathrm{i}}$ responses recovered partially during washout of TTX (Fig. 7I) $(n=3)$.

Additional quantification of the spatial decay in $\Delta F / F_{\max }$ revealed that in the presence of TTX, $\Delta F / F_{\max }$ values decayed to $37 \%$ within $17.5 \pm 0.5 \mu \mathrm{m}$ distance from soma (Fig. $7 H$ ) ( $n=3$ neurons). No significant difference was found for the decay obtained in the presence of TTX under I-clamp and $V$-clamp conditions, respectively ( $p>0.52$; data not shown). In contrast, the spatial decay of $\Delta F / F_{\max }$ was minimal, and in some cases $\Delta F / F_{\max }$ was even increased under control conditions (Fig. $7 H$ ).

Thus, in the presence of TTX, burst-like voltage commands only elicit $\left[\mathrm{Ca}^{2+}\right]_{\mathrm{i}}$ transients near the soma, but not at higherorder dendrites, suggesting that dendrites in spiny projection neurons are active. This would allow somatic action potentials to actively backpropagate into the dendrite.

$\leftarrow$

by somatic current injection reliably induced $\left[\mathrm{Ca}^{2+}\right]_{\mathrm{i}}$ transients throughout the neuron. $a-e$ are same as in $A$. A simultaneous, single-sweep measurement of $\left[\mathrm{Ca}^{2+}\right]_{\mathrm{i}}$ transients in soma and dendrites (upper traces, $380 \mathrm{~nm} ; \Delta 42 \mathrm{msec}$ illumination; $\Delta 120 \mathrm{msec}$ temporal resolution) and corresponding somatic burst firing (bottom traces) are shown. $C$, Onset of $\left[\mathrm{Ca}^{2+}\right]_{\mathrm{i}}$ transients correlated with the first action potential (from $B$, left bar). Symbols indicate center times for each frame acquisition. Circle, Soma; diamond, tertiary dendrites. $D$, Averaged normalized decay from $\Delta F / F_{\max }$ for each region (3 neurons; 3-4 up-states each). Note the slower time course at soma compared with dendrites and delayed action potential firing (arrow). 
A

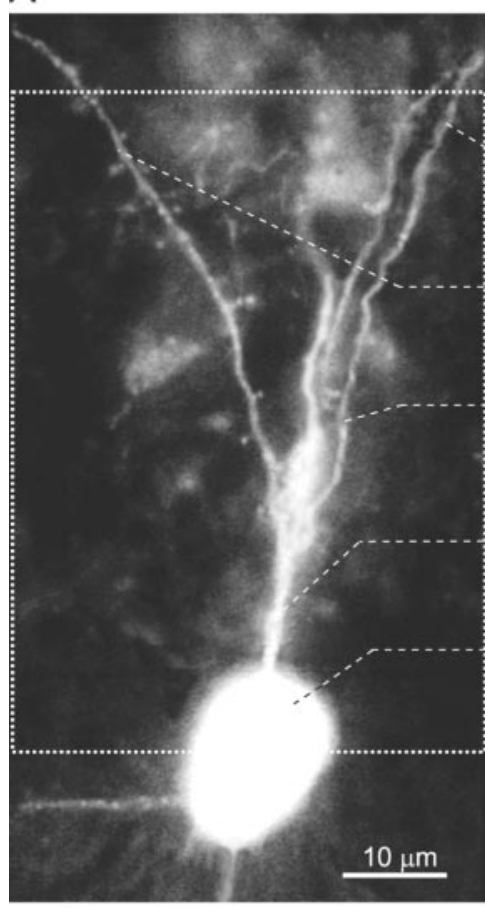

B
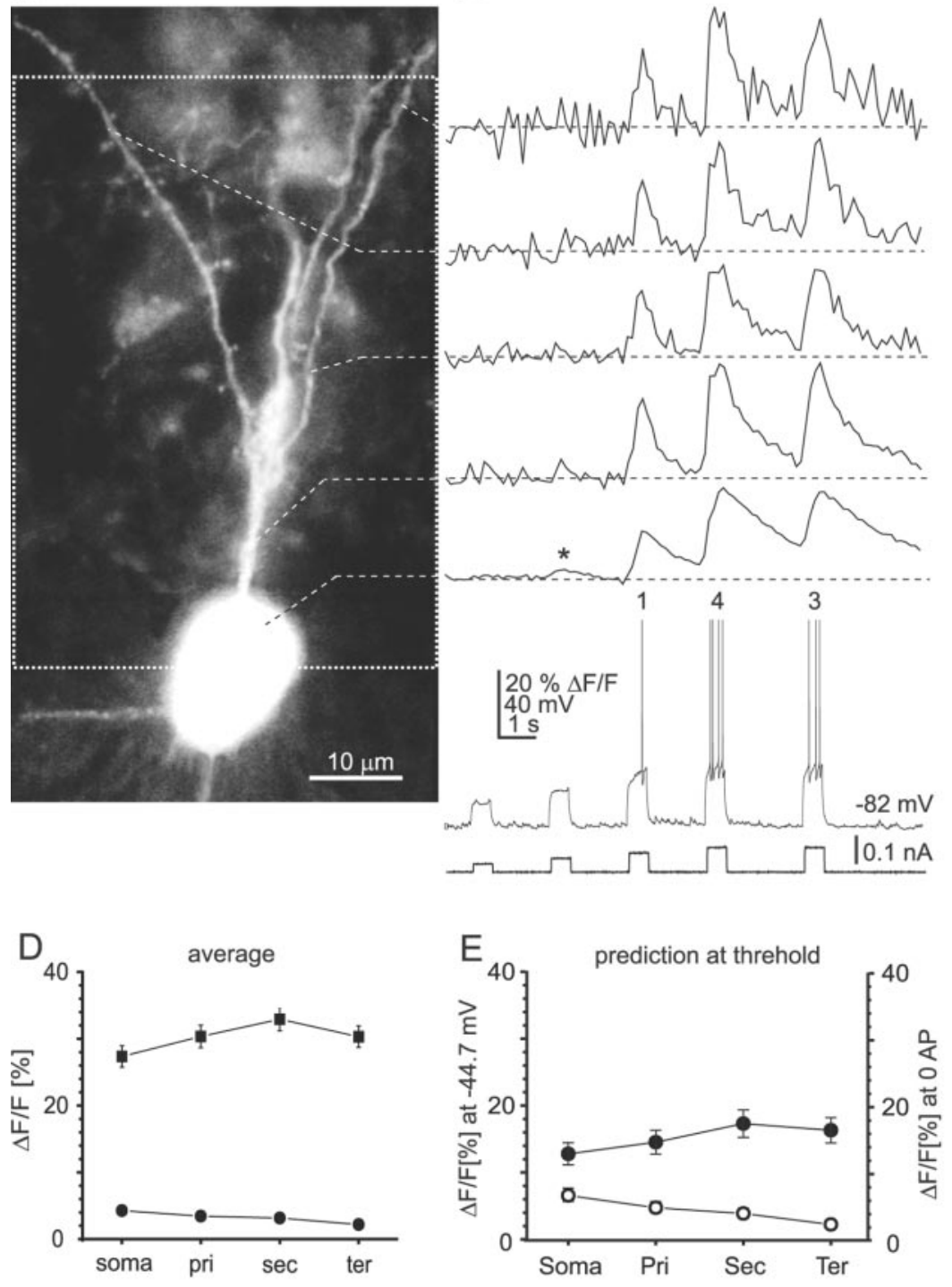

C
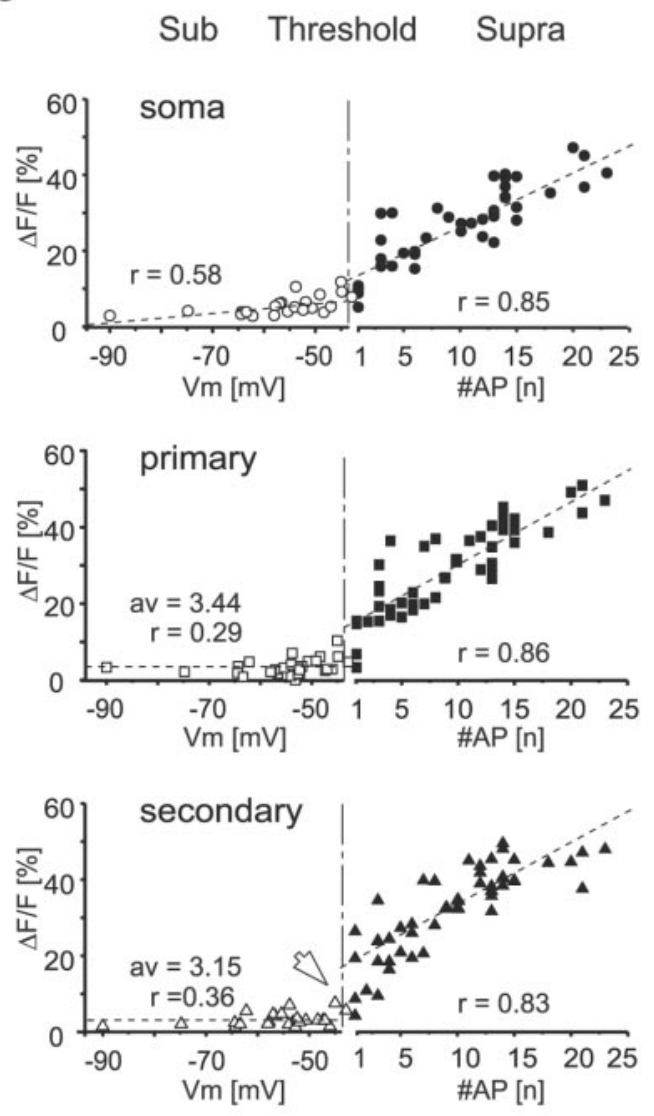

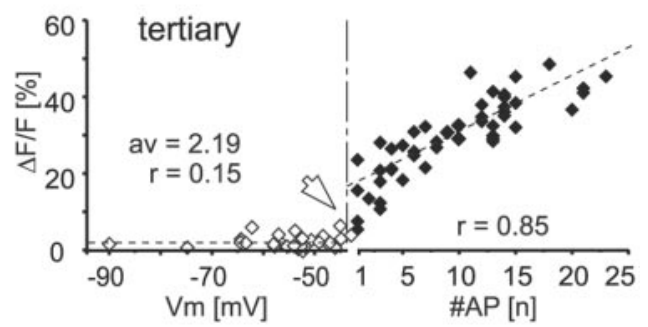

Figure 6. Dendritic $\left[\mathrm{Ca}^{2+}\right]_{\mathrm{i}}$ transients encode somatic burst firing but not subthreshold membrane potential during the down-state. $A$, Fluorescence image of the spiny projection neuron (Fura-2; $500 \mathrm{msec}$ exposure at $380 \mathrm{~nm} ; 10 \mathrm{~min}$ after break in). Dashed lines indicate ROIs located within the optical field of view (dotted box). B, Suprathreshold but not subthreshold somatic depolarizations $(500 \mathrm{msec})$ evoked $\left[\mathrm{Ca}^{2+}\right]_{\mathrm{i}}$ transients throughout the dendritic arbor and $\Delta F / F_{\max }$ values varied with the number of somatic action potentials (numbers). Note the small increase in $\Delta F / F_{\max }$ at soma close to threshold (asterisk). $C$, Dynamic range of $\Delta F / F_{\max }$ values for subthreshold and suprathreshold somatic depolarizations. Left, Dendritic $\Delta F / F_{\text {max }}$ values were not correlated with subthreshold somatic membrane potential depolarizations (open symbols; $n=14$ neurons; $1-2$ depolarizations per neuron). Right, $\Delta F / F_{\max }$ values linearly correlated with the number of action potentials in suprathreshold responses (closed symbols; $n=35$ neurons; $1-2$ depolarizations per neuron). Center, Dendritic $\Delta F / F_{\max }$ values revealed a discontinuous transition (open arrowheads) when moving from subthreshold to suprathreshold membrane potential responses. Broken vertical lines indicate a population action potential threshold of $-44.7 \mathrm{mV}$, which is aligned with 0 action potentials. Linear regression is indicated by dashed lines. av, Average $\Delta F / F$ for subthreshold depolarizing current pulses. Circle, Soma; square, primary dendrites; triangle, secondary dendrites; diamond, tertiary dendrites. $D$, Average $\Delta F / F_{\max }$ values were up to 10 times higher in suprathreshold responses compared with subthreshold responses. $E$, Discontinuity of $\Delta F / F_{\max }$ values in encoding the transition from subthreshold to suprathreshold responses to somatic current injection. Values from regression functions (mean $\pm 95 \%$ confidence interval) derived from subthreshold (open circles) and suprathreshold (closed circles) responses (from $C$, extrapolated to threshold and to 0 action potentials, respectively) are shown.

\section{Somatic action potentials increase dendritic $\left[\mathrm{Ca}^{2+}\right]_{\mathrm{i}}$ transients supralinearly during the up-state}

Electrophysiological properties and $\left[\mathrm{Ca}^{2+}\right]_{\mathrm{i}}$ dynamics of dendrites change considerably in the presence of synaptic activity when compared with resting conditions (Pare et al., 1998; Svoboda et al., 1999). Therefore, we tested whether somatic action potential bursts also increase dendritic $\left[\mathrm{Ca}^{2+}\right]_{\mathrm{i}}$ during up-states, which are driven by synaptic activity.

Previous experiments revealed that somatic current injections during the down-state elicited action potential firing with a delay of up to several hundreds of milliseconds (compare Figs. $1 A, 5 C$ ). For a suprathreshold depolarization pulse of $500 \mathrm{msec}$, six action potentials were elicited on average during the last $209 \pm 17 \mathrm{msec}$ ( $n=10$ neurons), equivalent to an average firing frequency of $28.7 \pm 2.4 \mathrm{~Hz}$. Correspondingly, a pulse length of $200 \mathrm{msec}$ and pulse amplitude of $0.1 \pm 0.02 \mathrm{nA}$ were used to elicit action potentials during up-states (Fig. 8).

Depolarizing somatic current pulses were injected $20 \mathrm{msec}$ 


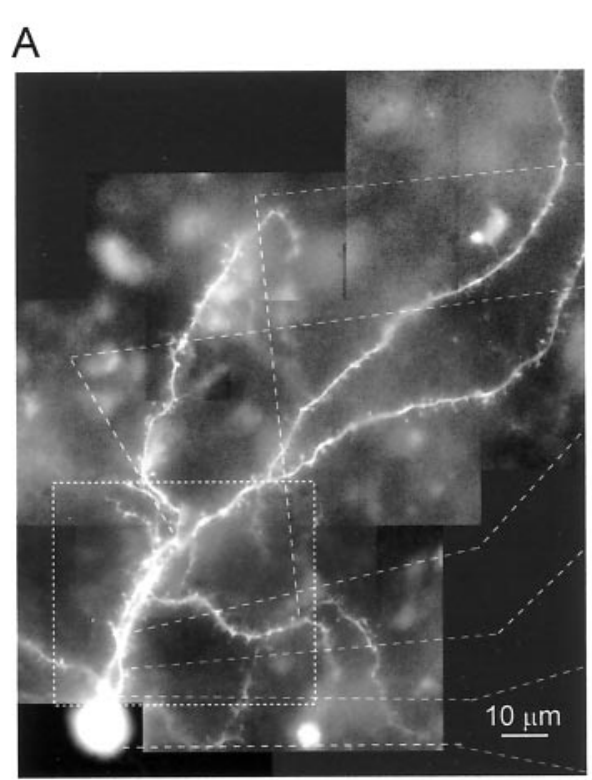
B Control
(I-clamp)
C TTX
(I-clamp)
D TTX
(V-clamp)
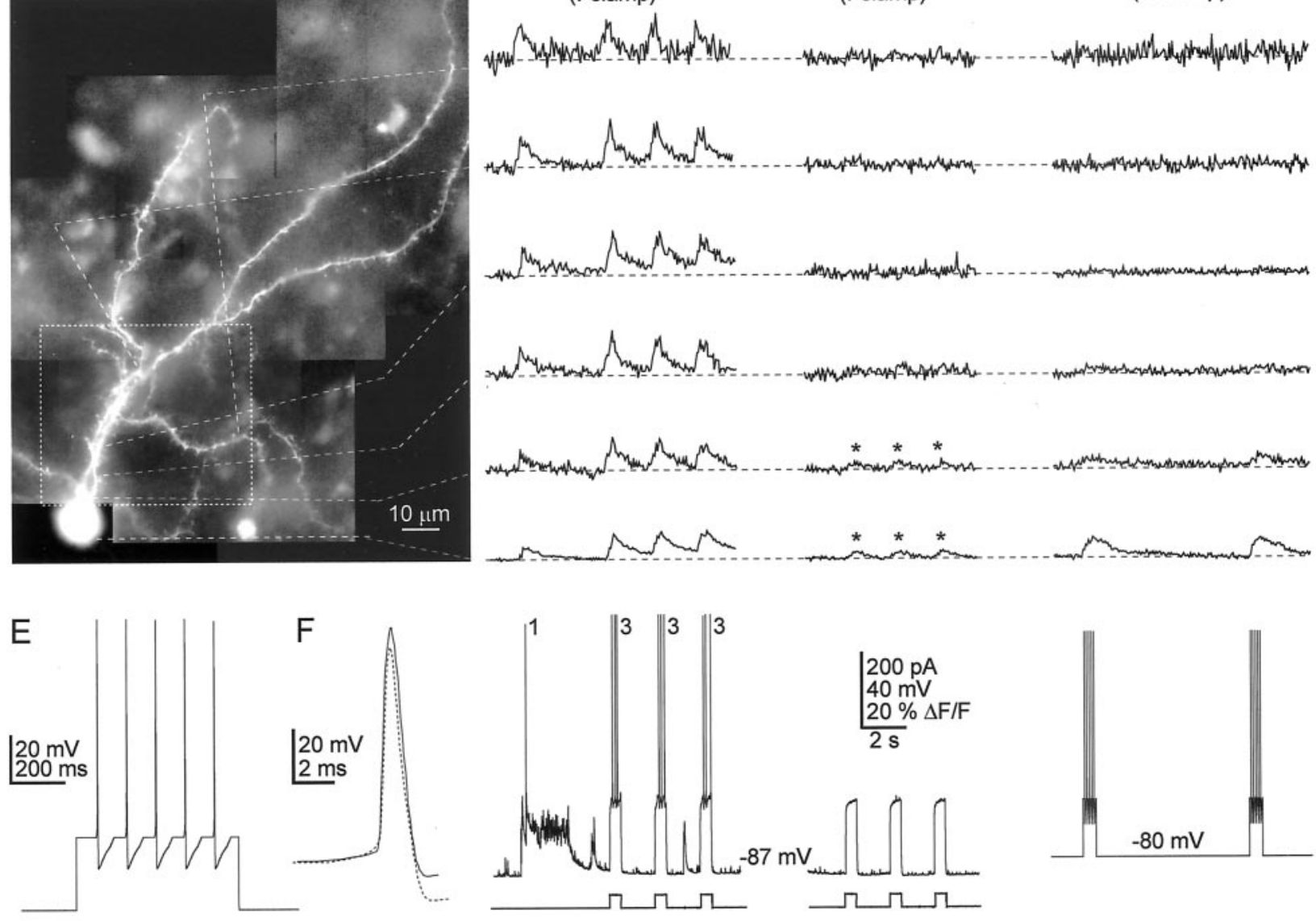

G

$\mathrm{H}$

I
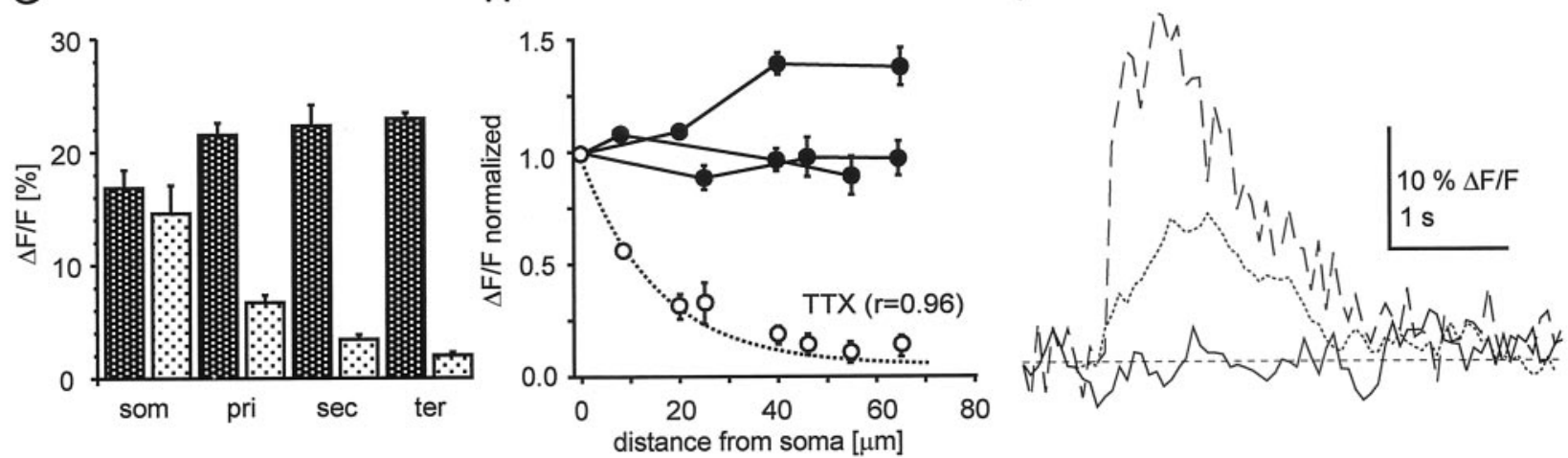

Figure 7. Action potential-evoked dendritic $\left[\mathrm{Ca}^{2+}\right]_{\mathrm{i}}$ transients are blocked by TTX. $A$, Fluorescence image of the spiny projection neuron (Fura-2; 1 sec exposure at $380 \mathrm{~nm} ; 50$ min after break in). Dashed lines indicate ROIs located within the optical field of view (dotted box). B, Simultaneous, single-sweep measurement of $\left[\mathrm{Ca}^{2+}\right]_{\mathrm{i}}$ transients in soma and dendrites (upper traces; $380 \mathrm{~nm} ; \Delta 42 \mathrm{msec}$ each frame; $\Delta 60 \mathrm{msec}$ resolution) and corresponding spontaneous intracellular neuronal activity at the soma (bottom trace). For the control (I-clamp), Spontaneous up-states and evoked somatic action potentials were correlated with $\left[\mathrm{Ca}^{2+}\right]_{\mathrm{i}}$ transients throughout the neuron. $C$, TTX (I-clamp): In the presence of TTX $(1 \mu \mathrm{M})$, the same somatic current injection elicited only weak $\left[\mathrm{Ca}^{2+}\right]_{\mathrm{i}}$ transients at soma and primary dendrites (asterisks). $D$, For TTX (V-clamp), a $V$-clamp command that mimicked an action potential burst elicited strong $\left[\mathrm{Ca}^{2+}\right]_{\mathrm{i}}$ transients at the soma, but failed to elicit $\left[\mathrm{Ca}^{2+}\right]_{\mathrm{i}}$ transients in higher-order dendrites. $E$, Enlarged time view of the $V$-clamp command applied in $D . F$, Overlay of the average evoked action potential obtained in $I$-clamp (dotted line) and the simulated action potential (solid line) used in the $V$-clamp command in $D$. $G$, In the presence of TTX, $\Delta F / F_{\text {max }}$ values were reduced in higher-order dendrites compared with controls but not in the soma. Dark bars, Control $I$-clamp with three neurons ( 3 trials per neuron, average of 5 action potentials). Light bars, TTX $V$-clamp, same ROIs and neurons as in the control. $H$, In the presence of TTX, action potential-evoked $\Delta F / F_{\text {max }}$ values decayed to $37 \%$ within $17 \mu \mathrm{m}$ from soma $(r=0.96$; single exponential fit). Closed circles, Control I-clamp with three neurons (5 trials per neuron, same ROIs). Open circles, TTX $V$-clamp, same neurons as in the control. I, Action potential-evoked dendritic $\left[\mathrm{Ca}^{2+}\right]_{\mathrm{i}}$ responses before (long dashed line), during (solid line), and after partial washout of TTX (10 min, dotted line). Each line is an average of three responses from the same neuron. 
A
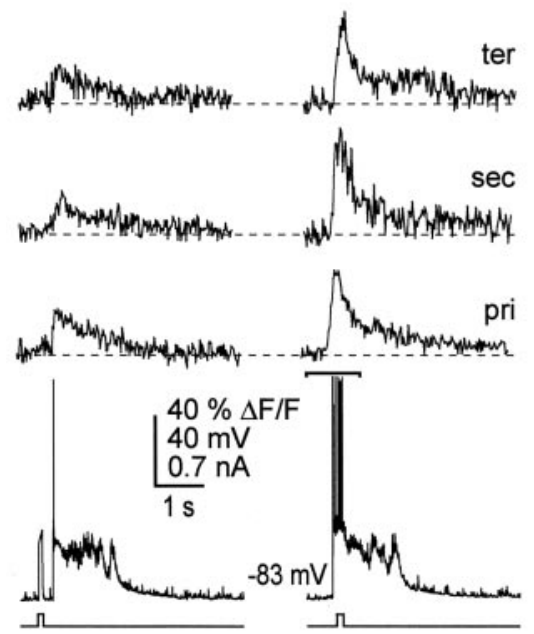

D

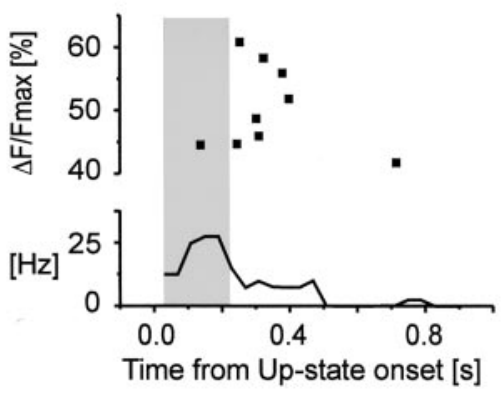

B
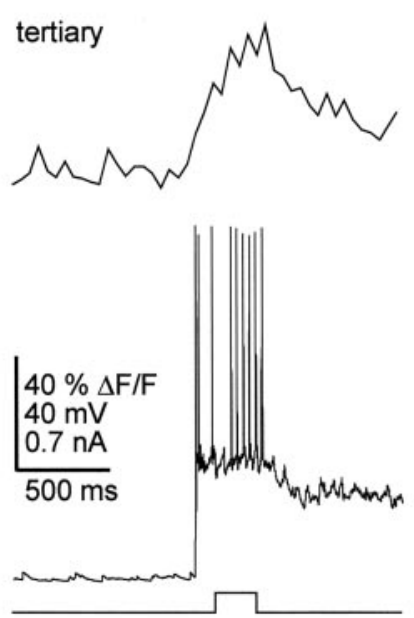

E

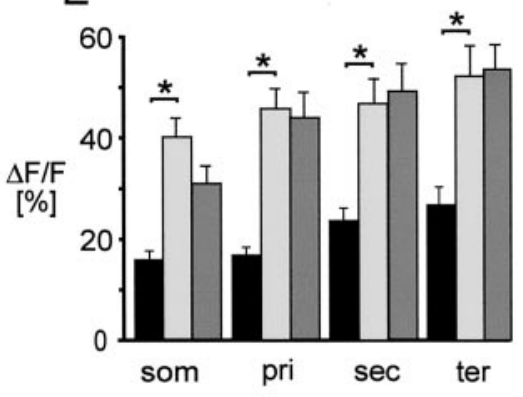

C

tertiary

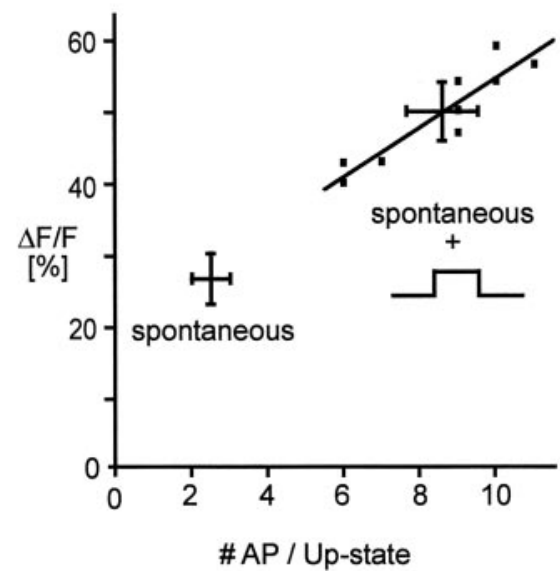

$\mathrm{F}$

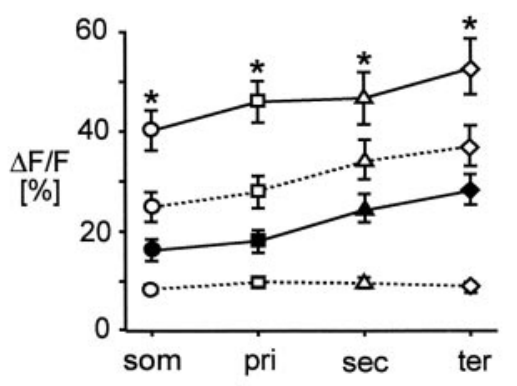

Figure 8. Supralinear dendritic $\left[\mathrm{Ca}^{2+}\right]_{\mathrm{i}}$ transients encode somatic bursts during up-states. $A$, Dendritic $\left[\mathrm{Ca}^{2+}\right]_{\mathrm{i}}$ transients $(380 \mathrm{~nm} ; \Delta 42 \mathrm{msec}$ each frame; $\Delta 60 \mathrm{msec}$ resolution) during up-state alone (left $)$ or with suprathreshold somatic current injection (right). Note the absence of $\left[\mathrm{Ca}{ }^{2+}\right]_{\mathrm{i}}$ transients in higher-order dendrites, when the depolarizing pulse occurs in the down-state. $B$, Detail of the resulting $\left[\mathrm{Ca}^{2+}\right]_{\mathrm{i}}$ transient in tertiary dendrites from up-state with somatic current injection. Note $\Delta F / F_{\max }$ at the end of the action potential burst (expanded from $A$, bar). $C$, Increasing the number of action potentials by somatic current injection increases $\Delta F / F_{\max }$ linearly in tertiary dendrites during up-states. Spontaneous up-states without somatic current injection averaged $2.5 \pm 0.5$ action potentials; spontaneous up-states with somatic current injection averaged $8.7 \pm 0.9$ action potentials. $D, \Delta F / F_{\text {max }}$ is reached after termination of somatic current injection. Individual $\Delta F / F_{\max }$ values (filled squares) are related to the time after up-state onset (tertiary dendrite). A peristimulus histogram of action potential frequency distribution (solid line) in relation to both up-state onset and somatic current injection is shown (shaded box). $E, \Delta F / F_{\max }$ values from up-states with injected action potentials were highly similar to population values reached during spontaneous up-states with identical numbers of action potentials. Dark bars, Up-states without somatic current injection and an average of $2.5 \pm 0.5$ spontaneous action potentials $\left(n=6\right.$ neurons). Medium bars, $\Delta F / F_{\max }$ from up-states with somatic current injection that resulted in an average of $8.7 \pm$ 0.9 action potentials ( $n=6$ neurons). Light bars, Up-states without somatic current injection and $8.7 \pm 0.9$ spontaneous action potentials $(n=21$ neurons; population data from regression analysis; $\left.{ }^{*} p<0.0001\right) . F$, Supralinear effect of backpropagating action potentials and synaptic inputs during up-states summarized for all compartments. Bottom solid line, Measured $\Delta F / F_{\max }$ for up-states without current injection and an average of 2.5 action potentials. Bottom broken line, Expected increase in $\Delta F / F_{\max }$ from 2.5 to 8.7 action potentials during the down-state. Middle broken line, Linear sum of both functions. Top solid line, Measured $\Delta F / F_{\max }$ during up-states with on average 2.5 spontaneous action potentials and 6.2 additional action potentials by somatic current injection $\left({ }^{*} p<0.0001\right)$.

after up-state onset in six neurons (Fig. $8 A, B$ ). In addition, up-states without current injection were sampled from each neuron (total of two to four up-states per neuron), and $\Delta F / F_{\max }$ values were pooled for both conditions and all neurons (Fig. $8 C, E)$, which averaged possible differences in synaptic inputs between both groups. These experiments revealed that somatic and dendritic $\left[\mathrm{Ca}^{2+}\right]_{i}$ were not saturated during spontaneous up-states, but were further increased by additional action potentials. On average, current injection increased the number of action potentials per up-state by $6.1 \pm 0.8$ (from $2.5 \pm 0.5$ to $8.6 \pm$ 0.9 action potentials), which resulted in an increase in $\Delta F / F_{\max }$ of 22-28\% (Fig. 8E) (soma to higher-order dendrites; $p<0.001$ ). Similar to current injection experiments in the down-state, these increases in $\Delta F / F_{\max }$ were highly correlated with the total number of action potentials (Fig. $8 C)(r=0.79 ; 0.80 ; 0.85 ; 0.92$; soma to tertiary dendrite).

$\left[\mathrm{Ca}^{2+}\right]_{\mathrm{i}}$ transients have been shown to correlate with action potential frequency (Helmchen et al., 1996); therefore, we tested whether the increased $\Delta F / F_{\max }$ during up-states with current injections resulted from transient firing rate increases that were not reflected in the total number of action potentials. Average firing frequency $\left(f_{\text {mean }}\right)$ during up-states with injected currents ranged from 10 to $30 \mathrm{~Hz}$, whereas maximal firing rates $\left(f_{\max }\right)$ ranged from 20 to $57 \mathrm{~Hz}$. The time course of average firing rate for all neurons is given in Figure $8 D$. We then tested which of these parameters accounted best for the observed increases in $\Delta F / F_{\max }$, using data from tertiary dendrites. Action potential number correlated most strongly with $\Delta F / F_{\max }(r=0.92)$ (Fig. 
$8 C)$ compared with $f_{\max }(r=0.20)$ or $f_{\text {mean }}(r=0.26)$. This strong correlation between the number of action potentials and $\Delta F / F_{\max }$ was present even when considering possible interactions with either $f_{\text {max }}$ or $f_{\text {mean }}(r=0.918$; partial correlation). The strong correlation with the total number of action potentials, which implies an accumulated increase of $\left[\mathrm{Ca}^{2+}\right]_{i}$ during the burst, was also supported by the finding that $\Delta F / F_{\max }$ on average occurred after termination of current injection (Fig. $8 D$ ).

Action potentials elicited by injecting current during up-states increased dendritic $\Delta F / F$ through propagation along the dendrite. This should be in contrast to dendritic $\Delta F / F$ during up-states with similar numbers of spontaneous action potentials driven by synaptic inputs. However, $\Delta F / F_{\max }$ values from up-states with current injections were very similar to $\Delta F / F_{\max }$ values reached during up-states with identical numbers of spontaneous action potentials (Figs. $3 C, 8 E$ ). More specifically, $\Delta F / F_{\max }$ values were identical in higher-order dendrites ( $p=0.81-0.99)$ and only slightly but nonsignificantly different at the soma $(p=0.21)$. This similarity suggests that dendritic $\left[\mathrm{Ca}^{2+}\right]_{\mathrm{i}}$ during up-states is largely determined by the number of action potentials and not synaptic inputs.

Finally, predicted increases in $\Delta F / F_{\max }$ systematically underestimated actual $\Delta F / F_{\max }$ increases during the up-state (Fig. $8 F$ ). Predictions in $\Delta F / F_{\max }$ for additional action potentials were obtained from down-state measurements. The predicted increase in $\Delta F / F_{\max }$ from three to nine action potentials during the downstate ranged between 8 and $10 \%$ (Figs. $6 C, 8 F$ ). The linear sum of $\Delta F / F_{\max }$ for spontaneous up-states without current injection plus predicted $\Delta F / F_{\max }$ values resulted in final $\Delta F / F_{\max }$ values of 25-37\% (soma, primary to tertiary dendrites). In contrast, actual $\Delta F / F_{\max }$ values measured during the up-state were $>10 \%$ $\Delta F / F_{\max }$ higher than predicted (Fig. $8 F$ ). This supralinearity, when expressed as a ratio between measured increase in the up-state and predicted increase from the down-state, was highly significant and reached $>200 \%$ for all compartments $(p<0.0001$; two-tailed $t$ test).

To summarize, dendritic $\left[\mathrm{Ca}^{2+}\right]_{\mathrm{i}}$ transients supralinearly encode somatic bursting in spiny projection neurons during upstates, which suggests an interaction between synaptic inputs and action potentials propagating along dendrites.

\section{DISCUSSION}

The main result from this study shows that during spontaneous up-states, information about somatic action potentials is present at higher-order dendrites. This information is likely to be communicated to dendrites through active backpropagation (Stuart and Sakmann, 1994; Stuart et al., 1997b; Häusser et al., 2000). The supralinear $\left[\mathrm{Ca}^{2+}\right]_{\mathrm{i}}$ signal represents a relatively simple code that contains information about a spiny projection neuron's contribution to basal ganglia output. This interaction between synaptic inputs, backpropagating action potentials, and corresponding dendritic $\left[\mathrm{Ca}^{2+}\right]_{\mathrm{i}}$ shows three characteristics. First, the dynamic range of dendritic $\left[\mathrm{Ca}^{2+}\right]_{\mathrm{i}}$ during up-states is balanced, allowing for continuous encoding of both synaptic inputs and somatic burst strength. During subthreshold up-states, the somatic peak membrane potential predicted $\left[\mathrm{Ca}^{2+}\right]_{\mathrm{i}}$ transients with relatively low corresponding $\Delta F / F_{\max }$ values $(<20 \%)$ throughout the dendritic tree. Bursts during up-states further correlated with additional increases of $\Delta F / F_{\max }$ by up to $40 \%$, a dynamic range increase of $200 \%$. Thus, synaptic inputs that depolarize spiny projection neurons into up-states do not saturate $\left[\mathrm{Ca}^{2+}\right]_{\mathrm{i}}$. This was also confirmed by the increase of $\Delta F / F_{\max }$ by additional action potentials through somatic current injection during up-states. Second, propagating action potentials rather than synaptic inputs dominate dendritic $\left[\mathrm{Ca}^{2+}\right]_{\mathrm{i}}$ transients during up-states. This interpretation is supported by the similarity of $\Delta F / F_{\max }$ between up-states with additional action potentials and spontaneous upstates with the same final number of action potentials. Finally, propagating action potentials increased dendritic $\left[\mathrm{Ca}^{2+}\right]_{i}$ supralinearly during up-states, because down-state measurements of evoked dendritic $\left[\mathrm{Ca}^{2+}\right]_{i}$ transients significantly underestimated up-state measurements.

Potentially, action potentials could be initiated in dendrites and propagate forward to the soma (Häusser et al., 2000). However, our results on subthreshold current injection show that the calcium signal decays within $17 \mu \mathrm{m}$ from the soma, suggesting a corresponding fast decrement in membrane potential over space (Figs. 6, 7). If the spike initiation zone is located far in higherorder dendrites, eliciting spikes by somatic current injections is difficult, unless the spike-initiation zone has a low threshold. The existence of subthreshold up-states, however, makes this possibility unlikely. Therefore, we conclude that the spike-initiation zone in spiny projection neurons is probably located close to the soma.

The present study used organotypic cultures containing cortex, striatum, and substantia nigra grown for 5-6 weeks. This in vitro model possesses several features that allow for the study of dendritic processing in mature striatal spiny projection neurons. First, spiny projection neurons can be studied during up-states and down-states with corticostriatal and nigrostriatal inputs present (Plenz and Kitai, 1998), although these inputs might be markedly reduced in overall numbers given the limited size of tissue taken for culturing. Second, the relatively thin cross section of the culture allows for the study of dendritic processing in higher-order dendrites without averaging and at relatively low concentrations of Fura-2.

\section{Propagation of action potentials in dendrites of spiny projection neurons}

The failure to elicit dendritic $\left[\mathrm{Ca}^{2+}\right]_{\mathrm{i}}$ transients in the presence of TTX using action potential trajectories as $V$-clamp commands implies that dendritic sodium channels are necessary for action potential propagation in spiny projection neurons. This finding extends previous ideas about nonlinear dendritic properties in these neurons (Wilson, 1995). The normalized spatial decay of $\left[\mathrm{Ca}^{2+}\right]_{\mathrm{i}}$ transients with distance from soma is close to the lengths of primary dendrites, suggesting that without regenerative sodium channels, higherorder dendrites in spiny projection neurons would be decoupled from somatic firing. Similar findings have been described for cortical neurons (Schiller et al., 1995) in which subsequent dendritic recordings showed the existence of action potential backpropagation (Stuart et al., 1997a).

The finding that action potential backpropagation in spiny projection neurons is actively maintained is consistent with other reports that show action potential backpropagation to be highly regulated (Stuart et al., 1997b). Action potential backpropagation is frequency dependent in hippocampal neurons (Callaway and Ross, 1995; Spruston et al., 1995; Larkum et al., 1999), is regulated by dendritic A-currents (Hoffman et al., 1997), depends on dendritic morphology (Vetter et al., 2001), and can be suppressed by inhibitory inputs (Kim et al., 1995; Buzsaki et al., 1996; Tsubokawa and Ross, 1996). The present study, by showing the existence of backpropagation during up-states, now allows additional investigation into the modu- 
lation of backpropagation under conditions similar to those in vivo.

\section{Supralinear $\left[\mathrm{Ca}^{2+}\right]_{i}$ transients during up-states}

The supralinear increase in dendritic $\left[\mathrm{Ca}^{2+}\right]_{\mathrm{i}}$ during up-states was highly correlated with the number of action potentials and less with average firing or peak firing frequency during the up-state. This finding is supported by the decay time constant of $500 \mathrm{msec}$ for dendritic calcium signals in our study. Such a time constant would favor the accumulation of the dendritic calcium signal over the relatively short duration of the up-state.

In cortical neurons, the coincidence of a backpropagating action potential with a subthreshold synaptic event gives rise to a $\left[\mathrm{Ca}^{2+}\right]_{\mathrm{i}}$ transient that is up to $200 \%$ larger than the sum of either event alone, which links somatic spikes with activated dendritic synapses (Denk et al., 1995; Yuste and Denk, 1995; Magee and Johnston, 1997; Markram et al., 1997; Koester and Sakmann, 1998; Schiller et al., 1998; Stuart and Häusser, 2001). In the present study, the magnitude in supralinearity was similar, but the source of this supralinearity is currently unclear in spiny projection neurons. In cortical pyramidal neurons, calcium, in addition to entering through voltage-gated calcium channels (VGCCs), also enters through NMDA channels, particularly when synaptic inputs coincide with backpropagating action potentials (Koester and Sakmann, 1998; Schiller et al., 1998). In addition, activation of $\mathrm{IP}_{3}$ and ryanodine receptors supralinearly increases dendritic $\left[\mathrm{Ca}^{2+}\right]_{\mathrm{i}}$ by releasing calcium from internal stores (Nakamura et al., 1999, 2000).

NMDA channels most likely contribute to dendritic $\left[\mathrm{Ca}^{2+}\right]_{\mathrm{i}}$ in spiny projection neurons. NMDA receptors have been immunohistochemically localized along their dendrites (Bernard and Bolam, 1998; Gracy et al., 1999), local NMDA application depolarizes spiny projection neurons (Cepeda and Levine, 1998; Cepeda et al., 1998), NMDA antagonists reduce evoked depolarizations (Kita, 1996), and calcium entry through NMDA receptors triggers immediate early gene expression (Konradi et al., 1996). Furthermore, VGCCs and internal stores could contribute to dendritic $\left[\mathrm{Ca}^{2+}\right]_{i}$ during up-states. Whole-cell recordings from acutely isolated spiny projection neurons established the presence of L-, N-, P-, Q-, and R-type VGCCs at the soma (Hoehn et al., 1993; Bargas et al., 1994; Song and Surmeier, 1996; Mermelstein et al., 1999; Foehring et al., 2000), some of which activate during action potential firing (Hernandez-Lopez et al., 1997; Vilchis et al., 2000). Similarly, receptors that release calcium from internal stores in pyramidal neurons have also been located in spiny projection neurons (Martone et al., 1997).

\section{Linking basal ganglia output to corticostriatal input through backpropagation}

The anatomical position of the striatum (for review, see Gerfen and Wilson, 1996) implies that spiny projection neurons play a major role in linking cortical activity to basal ganglia outputs (Alexander et al., 1986; Wurtz and Hikosaka, 1986; Albin et al., 1989; Chevalier and Deniau, 1990; Wise et al., 1996). Corticostriatal synapses are highly plastic (Lovinger et al., 1993; Calabresi et al., 1994; Akopian et al., 2000; Reynolds and Wickens, 2000; Kerr and Wickens, 2001), which suggests that modification of these synapses is a potential way to change basal ganglia outputs as a function of cortical inputs. The problem arises as to how to maintain corticostriatal input specificity given the highly convergent and divergent projections in the corticostriatal pathway (Percheron et al., 1984;
Bergman et al., 1998). Our findings suggest that spiny projection neurons influence both basal ganglia output and corticostriatal inputs directly. The encoding of somatic action potential bursts by dendritic $\left[\mathrm{Ca}^{2+}\right]_{i}$ provides direct evidence for information flow that is in opposite direction to the traditional idea of information processing in the basal ganglia. First, as we showed in this study, dendritic $\left[\mathrm{Ca}^{2+}\right]_{\mathrm{i}}$ levels correlate with the number of action potentials in spiny projection neurons (Fig. $3 C$ ). This would allow synapses from one corticostriatal projection neuron that terminate on different spiny projection neurons to independently experience $\left[\mathrm{Ca}^{2+}\right]_{\mathrm{i}}$ levels directly related to the output. Second, the supralinear increase in dendritic $\left[\mathrm{Ca}^{2+}\right]_{\mathrm{i}}$ during suprathreshold up-states in a single spiny projection neuron (Fig. $8 E, F$ ) might allow for the selection of those synapses that, through their activity, contributed to the up-state. In the cortex, synaptic activity through NMDA channels increases dendritic $\left[\mathrm{Ca}^{2+}\right]_{\mathrm{i}}$ locally (Regehr and Tank, 1994; Garaschuk et al., 1996; Finch and Augustine, 1998; Schiller et al., 1998; Emptage et al., 1999) that is both inputspecific (Muller and Connor, 1991) and supralinear when combined with a backpropagating action potential (Yuste and Denk, 1995; Koester and Sakmann, 1998; Maeda et al., 1999). Our findings suggest a similar mechanism for localizing plasticity to corticostriatal synapses in spiny projection neurons.

This interruption is supported by the findings that corticostriatal synaptic plasticity in spiny projection neurons is dependent on $\left[\mathrm{Ca}^{2+}\right]_{\mathrm{i}}$ as it is blocked by intracellular calcium chelators (Calabresi et al., 1994; Charpier and Deniau, 1998) and L-type VGCC antagonists (Akopian et al., 2000). Burst discharge during upstates that evoke supralinear $\left[\mathrm{Ca}^{2+}\right]_{\mathrm{i}}$ transients in higher-order dendrites therefore could be crucial in controlling this type of plasticity.

\section{REFERENCES}

Akopian G, Musleh W, Smith R, Walsh JP (2000) Functional state of corticostriatal synapses determines their expression of short- and longterm plasticity. Synapse 38:271-280.

Albin RL, Young AB, Penney JB (1989) The functional anatomy of basal ganglia disorders. Trends Neurosci 10:366-375.

Alexander GE, DeLong MR, Strick PL (1986) Parallel organization of functionally segregated circuits linking basal ganglia and cortex. Annu Rev Neurosci 9:357-381.

Bargas J, Howe A, Eberwine J, Cao Y, Surmeier DJ (1994) Cellular and molecular characterization of $\mathrm{Ca}^{2+}$ currents in acutely isolated, adult rat neostriatal neurons. J Neurosci 14:6667-6686.

Bergman H, Feingold A, Nini A, Raz A, Slovin H, Abeles M, Vaadia E (1998) Physiological aspects of information processing in the basal ganglia of normal and parkinsonian primates. Trends Neurosci 21:32-38.

Bernard V, Bolam JP (1998) Subcellular and subsynaptic distribution of the NR1 subunit of the NMDA receptor in the neostriatum and globus pallidus of the rat: co-localization at synapses with the GluR2/3 subunit of the AMPA receptor. Eur J Neurosci 10:3721-3736.

Buzsaki G, Penttonen M, Nadasdy Z, Bragin A (1996) Pattern and inhibition-dependent invasion of pyramidal cell dendrites by fast spikes in the hippocampus in vivo. Proc Natl Acad Sci USA 93:9921-9925.

Calabresi P, Pisani A, Mercuri NB, Bernardi G (1994) Post-receptor mechanisms underlying striatal long-term depression. J Neurosci 14:4871-4881.

Callaway JC, Ross WN (1995) Frequency-dependent propagation of sodium action potentials in dendrites of hippocampal CA1 pyramidal neurons. J Neurophysiol 74:1395-1403.

Cepeda C, Levine MS (1998) Dopamine and $N$-methyl-D-aspartate receptor interactions in the neostriatum. Dev Neurosci 20:1-18.

Cepeda C, Colwell CS, Itri JN, Chandler SH, Levine MS (1998) Dopaminergic modulation of NMDA-induced whole cell currents in neostriatal neurons in slices: contribution of calcium conductances. J Neurophysiol 79:82-94.

Charpier S, Deniau JM (1998) In vivo activity-dependent plasticity at cortico-striatal connections: evidence for physiological long-term potentiation. Proc Natl Acad Sci USA 94:7036-7040. 
Chevalier G, Deniau JM (1990) Disinhibition as a basic process in the expression of striatal functions. Trends Neurosci 13:277-280.

Crutcher MD, DeLong MR (1984) Single cell studies of the primate putamen. I. Functional organization. Exp Brain Res 53:233-243.

DeLong MR (1973) Putamen: activity of single units during slow and rapid arm movements. Science 179:1240-1242.

Denk W, Sugimori M, Llinas R (1995) Two types of calcium response limited to single spines in cerebellar Purkinje cells. Proc Natl Acad Sci USA 92:8279-8282

Emptage N, Bliss TV, Fine A (1999) Single synaptic events evoke NMDA receptor-mediated release of calcium from internal stores in hippocampal dendritic spines. Neuron 22:115-124.

Finch EA, Augustine GJ (1998) Local calcium signaling by inositol1,4,5-trisphosphate in Purkinje cell dendrites. Nature 396:753-756.

Foehring RC, Mermelstein PG, Song WJ, Ulrich S, Surmeier DJ (2000) Unique properties of R-type calcium currents in neocortical and neostriatal neurons. J Neurophysiol 84:2225-2236.

Garaschuk O, Schneggenburger R, Schirra C, Tempia F, Konnerth A (1996) Fractional $\mathrm{Ca}^{2+}$ currents through somatic and dendritic glutamate receptor channels of rat hippocampal CA1 pyramidal neurones. J Physiol (Lond) 491:757-772.

Gerfen CR, Wilson CJ (1996) The basal ganglia. In: Handbook of chemical neuroanatomy: integrated systems of the CNS, part III (Swanson LW, Bjoerklund A, Hoekfelt T, eds), pp 371-468. Amsterdam: Elsevier.

Gracy KN, Clarke CL, Meyers MB, Pickel VM (1999) N-methyl-Daspartate receptor 1 in the caudate-putamen nucleus: ultrastructural localization and co-expression with sorcin, a 22,000 molecular weight calcium binding protein. Neuroscience 90:107-117.

Groden DL, Guan Z, Stokes BT (1991) Determination of Fura-2 dissociation constants following adjustment of the apparent Ca-EGTA association constant for temperature and ionic strength. Cell Calcium 12:279-287.

Häusser M, Spruston N, Stuart GJ (2000) Diversity and dynamics of dendritic signaling. Science 290:739-744.

Helmchen F, Imoto K, Sakmann B (1996) $\mathrm{Ca}^{2+}$ buffering and action potential-evoked $\mathrm{Ca}^{2+}$ signaling in dendrites of pyramidal neurons. Biophys J 70:1069-1081.

Hernandez-Lopez S, Bargas J, Surmeier DJ, Reyes A, Galarraga E (1997) D1-receptor activation enhances evoked discharge in neostriatal medium spiny neurons by modulating an $\mathrm{L}$-type $\mathrm{Ca}^{2+}$ conductance. J Neurosci 17:3334-3342.

Hikosaka O, Sakamoto M, Usui S (1989) Functional properties of monkey caudate neurons. III. Activities related to expectation of target and reward. J Neurophysiol 61:814-832.

Hoehn K, Watson TW, MacVicar BA (1993) Multiple types of calcium channels in acutely isolated rat neostriatal neurons. J Neurosci 13:1244-1257.

Hoffman DA, Magee JC, Colbert CM, Johnston D (1997) $\mathrm{K}^{+}$channel regulation of signal propagation in dendrites of hippocampal pyramidal neurons. Nature 387:869-875.

Jaeger D, Gilman S, Aldridge JW (1993) Primate basal ganglia activity in a precued reaching task: preparation for movement. Exp Brain Res 95:51-64.

Jog MS, Kubota Y, Connolly CI, Hillegaart V, Graybiel AM (1999) Building neural representations of habits. Science 286:1745-1749.

Kerr JND, Wickens JR (2001) Dopamine D-1/D-5 receptor activation is required for long-term potentiation in the rat neostriatum in vitro. J Neurophysiol 85:117-124.

Kim HG, Beierlein M, Connors BW (1995) Inhibitory control of excitable dendrites in neocortex. J Neurophysiol 74:1810-1814.

Kimura M, Aosaki T, Ishida A, Watanabe K (1992) Activity of primate putamen neurons is selective to the mode of voluntary movement: visually guided, self-initiated, or memory guided. Exp Brain Res 89:473-477.

Kita H (1996) Glutamatergic and GABAergic postsynaptic responses of striatal spiny neurons to intrastriatal and cortical stimulation recorded in slice preparations. Neuroscience 70:925-940.

Koester HJ, Sakmann B (1998) Calcium dynamics in single spines during coincident pre- and postsynaptic activity depend on relative timing of back-propagating action potentials and subthreshold excitatory postsynaptic potentials. Proc Natl Acad Sci USA 95:9596-9601.

Konradi C, Leveque JC, Hyman SE (1996). Amphetamine and dopamine-induced immediate early gene expression in striatal neurons depends on postsynaptic NMDA receptors and calcium. J Neurosci 16:4231-4239.

Koos T, Tepper JM (1999) Inhibitory control of neostriatal projection neurons by GABAergic interneurons. Nat Neurosci 2:467-472.

Larkum ME, Kaiser KM, Sakmann B (1999) Calcium electrogenesis in distal apical dendrites of layer 5 pyramidal cells at a critical frequency of back-propagating action potentials. Proc Natl Acad Sci USA 96:14600-14604.

Lovinger DM, Tyler EC, Merritt A (1993) Short- and long-term synaptic depression in rat neostriatum. J Neurophysiol 70:1937-1949.

Maeda H, Ellis-Davies GCR, Ito K, Miyashita Y, Kasai H (1999) Su- pralinear $\mathrm{Ca}^{2+}$ signaling by cooperative and mobile $\mathrm{Ca}^{2+}$ buffering in Purkinje neurons. Neuron 24:989-1002.

Magee JC, Johnston D (1997) A synaptically controlled, associative signal for Hebbian plasticity in hippocampal neurons. Science 275:209-213.

Markram H, Lübke J, Frotscher M, Sakmann B (1997) Regulation of synaptic efficacy by coincidence of postsynaptic action potentials and EPSPs. Science 275:213-215.

Martone ME, Alba SA, Edelman VM, Airey JA, Ellisman MH (1997) Distribution of inositol-1,4,5-trisphosphate and ryanodine receptors in rat neostriatum. Brain Res 756:9-21.

Mermelstein PG, Foehring RC, Tkatch T, Song. WJ, Baranauskas G, Surmeier DJ (1999) Properties of Q-type calcium channels in neostriatal and cortical neurons are correlated with $\beta$ subunit expression. J Neurosci 19:7268-7277.

Muller W, Connor JA (1991) Dendritic spines as individual neuronal compartments for synaptic $\mathrm{Ca}^{2+}$ responses. Nature 354:73-76.

Nakamura T, Barbara JG, Nakamura K, Ross WN (1999) Synergistic release of $\mathrm{Ca}^{2+}$ from $\mathrm{IP}_{3}$-sensitive stores evoked by synaptic activation of mGluRs paired with backpropagating action potentials. Neuron 24:727-737.

Nakamura T, Nakamura K, Lasser-Ross N, Barbara JG, Sandler VM, Ross WN (2000) Inositol 1,4,5-trisphosphate $\left(\mathrm{IP}_{3}\right)$-mediated $\mathrm{Ca}^{2+}$ release evoked by metabotropic agonists and backpropagating action potentials in hippocampal CA1 pyramidal neurons. J Neurosci 20:8365-8376.

Neher E (1992) Correction for liquid junction potentials in patch clamp experiments. Methods Enzymol 20:123-131.

Neher E, Augustine GJ (1992) Calcium gradients and buffers in bovine chromaffin cells. J Physiol (Lond) 450:273-301.

Nisenbaum ES, Wilson CJ (1995) Potassium currents responsible for inward and outward rectification in rat neostriatal spiny projection neurons. J Neurosci 15:4449-4463.

Pare D, Shink E, Gaudreau H, Destexhe A, Lang EJ (1998) Impact of spontaneous synaptic activity on the resting properties of cat neocortical pyramidal neurons in vivo. J Neurophysiol 79:1450-1460.

Percheron G, Yelnik J, François C (1984) A Golgi analysis of the primate globus pallidus. III. Spatial organization of the strio-pallidal complex. J Comp Neurol 227:214-227.

Plenz D, Aertsen A (1996) Neuronal dynamics in cortex-striatum cocultures. II. Spatio-temporal characteristics of neuronal activity. Neuroscience 70:893-924.

Plenz D, Kitai ST (1998) "Up" and "down" states in striatal medium spiny neurons simultaneously recorded with spontaneous activity in fast-spiking interneurons studied in cortex-striatum-substantia nigra organotypic cultures. J Neurosci 18:266-283.

Regehr WG, Tank DW (1994) Dendritic calcium dynamics. Curr Opin Neurobiol 4:373-382.

Reynolds JN, Wickens JR (2000) Substantia nigra dopamine regulates synaptic plasticity and membrane potential fluctuations in the rat neostriatum in vivo. Neuroscience 99:199-203.

Schiller J, Helmchen F, Sakmann B (1995) Spatial profile of dendritic calcium transients evoked by action potentials in rat neocortical pyramidal neurones. J Physiol (Lond) 487:583-600.

Schiller J, Schiller Y, Clapham DE (1998) NMDA receptors amplify calcium influx into dendritic spines during associative pre- and postsynaptic activation. Nat Neurosci 1:114-118.

Song WJ, Surmeier DJ (1996) Voltage-dependent facilitation of calcium channels in rat neostriatal neurons. J Neurophysiol 76:2290-2306.

Spruston N, Schiller Y, Stuart S, Sakmann B (1995) Activity-dependent action potential invasion and calcium influx into hippocampal CA1 dendrites. Science 268:297-300.

Stern EA, Kincaid AE, Wilson CJ (1997) Spontaneous subthreshold membrane potential fluctuations and action potential variability of rat corticostriatal and striatal neurons in vivo. J Neurophysiol 77:1697-1715.

Stuart G, Schiller J, Sakmann B (1997a) Action potential initiation and propagation in rat neocortical pyramidal neurons. J Physiol (Lond) 505:617-632.

Stuart G, Spruston N, Sakmann B, Häusser M (1997b) Action potential initiation and backpropagation in neurons of the mammalian CNS Trends Neurosci 20:125-131.

Stuart GJ, Häusser M (2001) Dendritic coincidence detection of EPSPs and action potentials. Nat Neurosci 4:63-71.

Stuart GJ, Sakmann B (1994) Active propagation of somatic action potentials into neocortical pyramidal cell dendrites. Nature 367:69-72.

Surmeier DJ, Bargas J, Kitai ST (1989) Two types of A-current differing in voltage-dependence are expressed by neurons of the rat neostriatum. Neurosci Lett 103:331-337.

Svoboda K, Helmchen F, Denk W, Tank DW (1999) Spread of dendritic excitation in layer $2 / 3$ pyramidal neurons in rat barrel cortex in vivo. Nat Neurosci 2:65-73.

Tremblay L, Hollerman JR, Schultz W (1998) Modifications of reward expectation-related neuronal activity during learning in primate striatum. J Neurophysiol 80:964-977. 
Tsubokawa H, Ross WN (1996) IPSPs modulate spike backpropagation and associated $\left[\mathrm{Ca}^{2+}\right]_{i}$ changes in the dendrites of hippocampal CA1 pyramidal neurons. J Neurophysiol 76:2896-2906.

Turner DA (1984) Segmental cable evaluation of somatic transients in hippocampal neurons (CA1, CA3, and dentate). Biophys J 46:73-84.

Vetter P, Roth A, Häusser M (2001) Propagation of action potentials in dendrites depends on dendritic morphology. J Neurophysiol 85:926-937.

Vilchis C, Bargas J, Ayala GX, Galvan E, Galarraga E (2000) $\mathrm{Ca}^{2+}$ channels that activate $\mathrm{Ca}^{2+}$-dependent $\mathrm{K}^{+}$currents in neostriatal neurons. Neuroscience 95:745-752.

Wilson CJ (1995) Dynamic modification of dendritic cable properties and synaptic transmission by voltage-gated potassium channels. J Comput Neurosci 2:91-115.
Wilson CJ, Kawaguchi Y (1996) The origins of two-state spontaneous membrane potential fluctuations of neostriatal spiny neurons. J Neurosci 16:2397-2410.

Wilson CJ, Chang HT, Kitai ST (1983) Disfacilitation and longlasting inhibition of neostriatal neurons in the rat. Exp Brain Res $51: 227-235$.

Wise SP, Murray EA, Gerfen CR (1996) The frontal cortex-basal ganglia system in primates. Crit Rev Neurobiol 10:317-356.

Wurtz RH, Hikosaka O (1986) Role of the basal ganglia in the initiation of saccadic eye movements. Prog Brain Res 64:175-190.

Yuste R, Denk W (1995) Dendritic spines as basic functional units of neuronal integration. Nature 375:682-684. 